\title{
Tuning of the Copper-Zirconia Phase Boundary for Selectivity Control of Methanol Conversion
}

Lukas Mayr ${ }^{1,2}$, Xuerong Shi $^{1}$, Norbert Köpfle ${ }^{1}$, Bernhard Klötzer ${ }^{1}$, Dmitry Y. Zemlyanov ${ }^{2}$ and Simon Penner ${ }^{1, *}$

${ }^{1}$ Institute of Physical Chemistry, University of Innsbruck, Innrain 80-82, Innsbruck, Austria

${ }^{2}$ Birck Nanotechnology Center, Purdue University, 1205 West State Street, West Lafayette, IN 47907-2057, USA

Corresponding author: Tel: +43 512507 58003, E-mail: simon.penner@uibk.ac.at Keywords: $\mathrm{Cu} \mathrm{Zr}$ inverse model system - methanol steam reforming - water activation . surface redox chemistry $\cdot$ phase boundary $\cdot$ chemical vapour deposition 


\begin{abstract}
Chemical-vapor deposition $(\mathrm{CVD})$ of a $\mathrm{Zr}-(\mathrm{O}-\mathrm{tBu})_{4}$ precursor on different $\mathrm{Cu}$ substrates was used to prepare model systems for $\mathrm{ZrO}_{\mathrm{x}} \mathrm{H}_{\mathrm{y}}-\mathrm{Cu}$ catalysts and to test their reactivity and selectivity in methanol steam reforming (MSR). A partially hydroxylated and initially fully oxidized submonolayer $\mathrm{ZrO}_{\mathrm{x}} \mathrm{H}_{\mathrm{y}}$ surface species results, exhibiting a pronounced catalytic synergism between the $\mathrm{ZrO}_{\mathrm{x}} \mathrm{H}_{\mathrm{y}}$ overlayer and $\mathrm{Cu}$ only with respect to partial methanol deydrogenation to formaldehyde. Thus, it differs strongly from in situ grown $\mathrm{ZrO}_{\mathrm{x}} \mathrm{H}_{\mathrm{y}}$ layers on $\mathrm{Cu}$ formed from an initially bimetallic mixed $\mathrm{Zr} / \mathrm{ZrO}_{\mathrm{x}}$ state under MSR conditions. CVDgrown $\mathrm{Zr}-\mathrm{OH}$ groups are not stable under MSR conditions, thus reversible in situ hydroxylation and water-activating reaction channels are suppressed. Comparison of both model systems indicates that only a dedicated $\mathrm{Cu}-\mathrm{ZrO}_{\mathrm{x}} \mathrm{H}_{\mathrm{y}}$ interface with in situ formed and reversibly hydroxylated sites, accessible only from initially (inter)metallic $\mathrm{Cu} / \mathrm{Zr}$ species at the surface, leads to water activation, total oxidation of intermediate formaldehyde and enhanced $\mathrm{CO}_{2}$ selectivity.
\end{abstract}




\section{Introduction}

Copper-based catalysts are widely used for applications in methanol chemistry, whereby controllable steering of product selectivity is a key criterion for technical usage. This particularly applies to the technical formaldehyde production from methanol. The other examples are methanol synthesis from syngas with optimized $\mathrm{CO} / \mathrm{CO}_{2}$ ratio, hydrogenation/photo-reduction of $\mathrm{CO}_{2}$ [1] to produce "renewable" methanol, and methanol steam reforming (MSR) as the reversal of the synthesis reaction from $\mathrm{CO}_{2}$. MSR is an important route for $\mathrm{H}_{2}$ synthesis. In order to realize the efficient on-board production of clean hydrogen in automotive applications, the key targets of MSR are high $\mathrm{CO}_{2}$ selectivity, low $\mathrm{CO}$ content and maximum $\mathrm{H}_{2}$ yield [2]. Methanol partial oxidation is performed on $\mathrm{Cu}$-based catalysts trimmed towards maximum formaldehyde selectivity [3], where in situ observed subsurface oxygen is likely highly relevant and plays a key role $[4,5]$. All these systems trigger different reaction channels on $\mathrm{Cu}$ via various dopants. Three kinds of catalytic relevant $\mathrm{Cu}$ surfaces can be defined: very clean $\mathrm{Cu}$ that provides no sites for methanol (and water) activation, subsurface activated $\mathrm{Cu}$ that opens partial oxidation reaction routes by enabling $\mathrm{MeOH}$ activation and $\mathrm{H}_{2}$ desorption but at the same time stabilizing formaldehyde, and bifunctional $\mathrm{Cu}$ surfaces/interfaces that, via $\mathrm{Cu}$ interaction with dopant atoms/ species, provide sites for $\mathrm{H}_{2} \mathrm{O}$ activation and methanol activation at the same time [6]. Therefore, clear understanding of $\mathrm{Cu}$-dopant interactions is inevitable for the further development and improvement of industrially applied catalysts, especially upon consideration that enormous differences in product-selectivity can be obtained by small, but directed changes in the catalyst preparation procedure. Selectivity control is thereby realized by suppression of full dehydrogenation of methanol to $\mathrm{CO}$ and subsequent promotion of desired partial or total reaction channels, that is, either formaldehyde formation via partial dehydrogenation and fast desorption or, for MSR, total oxidation of intermediate oxygenates, such as $\mathrm{HCHO}$, to $\mathrm{CO}_{2}$ by co-adsorbed water. 
With respect to the catalytic function of zirconia, already the simple addition of $\mathrm{ZrO}_{2}$ to the conventionally used $\mathrm{Cu} / \mathrm{ZnO}$ catalysts allows not only for reducing the inherent drawback of purely $\mathrm{ZnO}$-based catalysts, that is, the poor sintering stability of the $\mathrm{Cu}$ particles, but also to enhance MSR selectivity [2]. Synergistic $\mathrm{Cu}-\mathrm{ZrO}_{2}$ interactions have also been reported for $\mathrm{Cu} / \mathrm{ZrO}_{2}$ catalysts without $\mathrm{ZnO}$, involving $\mathrm{Cu}-\mathrm{O}-\mathrm{Zr}$ bonds at the phase boundary, which are believed to play a crucial role in steering the methanol reforming reaction to maximize $\mathrm{CO}_{2}$ selectivity [7-10]. Specifically, a nanocrystalline copper/tetragonal $\mathrm{ZrO}_{2}$ catalyst synthesized by a polymer templating technique [6] was reported to be more active, more $\mathrm{CO}_{2}$-selective and more stable in MSR than the technical $\mathrm{Cu} / \mathrm{ZnO} / \mathrm{Al}_{2} \mathrm{O}_{3}$ methanol synthesis catalyst [11]. Although a beneficial effect of the redox chemistry of $\mathrm{Cu}$ and the $\mathrm{Cu}^{0} / \mathrm{Cu}^{\text {oxidized }}$ ratio at the interface is put forward as an important selectivity descriptor, alongside disorder and strain phenomena within the metallic $\mathrm{Cu}$ phase [2], contradicting influence has also been reported. Both beneficial $[7,8]$ and adverse [10] effects of the reducibility of $\mathrm{Cu}$ are found in literature. Nevertheless, any influence appears strongly connected to the quantity and quality of the, especially in situ formed, $\mathrm{Cu}-\mathrm{ZrO}_{2}$ interface. This is important insofar as also the oxide part of the catalyst may synergistically participate in the reaction, either by stabilizing oxygenate intermediates or by activating water [2]. The latter has already been identified on the corresponding $\mathrm{Pd}-\mathrm{ZnO}[12]$ and $\mathrm{Cu}-\mathrm{ZnO}$ [13] systems as the most important step in $\mathrm{CO}_{2^{-}}$ selective steam reforming.

As it is known from previous studies on an intermetallic $\mathrm{Cu}-\mathrm{Zr}$ pre-catalyst state [14] and the works of other groups [6], a $\mathrm{Cu} / \mathrm{ZrO}_{2}$ or $\mathrm{Cu} / \mathrm{ZrO}_{\mathrm{x}} \mathrm{H}_{\mathrm{y}}$ interface, providing active and selective sites for the methanol steam reforming (MSR) reaction, is a structural pre-requisite. Furthermore, it is crucial to obtain a bi-functional surface that can activate methanol and water at the same time for high $\mathrm{CO}_{2}$ selectivity and consequently, a high $\mathrm{H}_{2}$ yield with minimized $\mathrm{CO}$ contamination. 
The partial oxidation of methanol to formaldehyde, a process of high industrial relevance, applies the different requirements for a catalytic surface. No water activation is required. However, efficient methanol activation along with stabilization of formaldehyde against full dehydrogenation and selective oxidative removal of $\mathrm{H}_{2}$ is still required. For the latter, $\mathrm{O}_{2^{-}}$ activation toward a suitable oxygen surface/subsurface species, which should mainly react with $\mathrm{H}_{2}$ toward water and not with formaldehyde toward formates $/ \mathrm{CO}_{2}$, is mandatory. Although specifically activated $\mathrm{O}_{\text {sub }} / \mathrm{Cu}$ itself can provide the selective dehydrogenation/ $\mathrm{H}_{2^{-}}$ oxidation functionality [15], i.e. providing active sites both for methanol activation and for formaldehyde stabilization, this otherwise dopant-free form of $\mathrm{Cu}$ at the same time only poorly activates water. Moreover, as shown in this work, ultra-clean and oxygen-free copper is hardly active for both processes. The activation for formaldehyde formation is shown and discussed in detail in the first part of the catalytic section of this work (3.B.). Water activation and $\mathrm{H}_{2}$ desorption are obviously provided by the $\mathrm{ZrO}_{\mathrm{x}} \mathrm{H}_{\mathrm{y}}$ species originating from $\mathrm{Zr}^{0}$ oxidation/hydroxylation, and their chemical state is as important as their surface structure (essentially differing from bulk $\mathrm{ZrO}_{2}$ structures, since the overlayer thickness is $<1 \mathrm{ML}$ ). As for specific $\mathrm{Cu}-\mathrm{ZrO}_{2}$ systems, the interface of $\mathrm{CuO}$ with tetragonal $\mathrm{ZrO}_{2}$, prepared via a solgel technique, showed high $\mathrm{CO}_{2}$-selectivity and acceptable activity [6]. $\mathrm{O}_{2}$ /air oxidation of a $\mathrm{Cu}-\mathrm{Zr}$ glassy alloy was investigated, however the activity and selectivity was found to be not satisfying $[16,17]$ and, therefore, an additional additive of novel metals is required for these systems. This indicates the absence of active $\mathrm{Cu} / \mathrm{ZrO}_{\mathrm{x}} \mathrm{H}_{\mathrm{y}}$ sites, most likely due to high temperature oxidative treatments and also brings along new $\mathrm{CO}_{2}$-selectivity issues by i.e. the opening of a full dehydrogenation pathway on $\mathrm{Pd}$.

On the other hand, our own dedicated model catalyst studies showed enhanced $\mathrm{CO}_{2}$ selectivity for an in situ oxidized, initially $\mathrm{Cu} / \mathrm{Zr}^{0}$ bimetallic state, intimately linked to reversible surface hydroxylation and associated formation of $\mathrm{ZrO}_{\mathrm{x}} \mathrm{H}_{\mathrm{y}}$ layers [14]. Whether initially hydroxylated $\mathrm{ZrO}_{\mathrm{x}} \mathrm{H}_{\mathrm{y}}$ species formed via CVD of $\mathrm{Zr}(\mathrm{O}-\mathrm{tBu})_{4}(\mathrm{ZTB})$ could feature 
the same positive effects on the $\mathrm{CO}_{2}$-selectivity (providing comparably active and selective sites in terms of formaldehyde stabilization and $\mathrm{H}_{2} \mathrm{O}$ activation) represented the original focus of this study.

In the present study we exemplify the surprising and unexpected versatility of differently prepared inverse $\mathrm{Cu}-\mathrm{ZrO}_{\mathrm{x}} \mathrm{H}_{\mathrm{y}}$ phase boundary model systems for selective control of these reaction channels. Specifically, focus was put on the growth of $\mathrm{ZrO}_{\mathrm{x}} \mathrm{H}_{\mathrm{y}}$ submonolayers on $\mathrm{Cu}$ by chemical vapor deposition (CVD) with the prime intention to prepare a catalytically active, bi-functional $\mathrm{Cu}-\mathrm{ZrO}_{\mathrm{x}} \mathrm{H}_{\mathrm{y}}$ interface. The $\mathrm{CVD}$-prepared layer therefore was not supposed to act as a fully surface-covering protection layer like in many other ALD/CVD applications [15], but to be a co-functional part of the catalytically active interfacial species itself.

In due course, the growth, annealing behavior and associated catalytic performance of these CVD-prepared model catalysts has been thoroughly tested. Both a $\mathrm{Cu}(111)$ single crystal and a polycrystalline $\mathrm{Cu}$ foil were chosen as substrates and (sub)monolayers of $\mathrm{ZrO}_{\mathrm{x}} \mathrm{H}_{\mathrm{y}}$ were accordingly prepared by exposure to gaseous ZTB in a UHV chamber with an attached highpressure reaction cell. State-of-the art surface science characterization of the pre- and postcatalysis states of the model surfaces was performed using X-ray Photoelectron Spectroscopy (XPS), Low-energy Ion Scattering Spectroscopy (LEIS), High-resolution Electron-Energy Loss Spectroscopy (HREELS) and Scanning Tunneling Microscopy (STM) and combined with dedicated reactivity studies in the UHV-compatible high-pressure catalytic reaction cell. Particular emphasis was given to a direct comparison of the model systems under otherwise identical experimental conditions in order to ensure quantitative comparability of rates and selectivities. Theoretical calculations (DFT) have been performed to substantiate the experimental results.

\section{Experimental Setup}


Two dedicated UHV chambers with complementary techniques were used for preparation and analysis and the corresponding results correlated via XP spectroscopy (i.e. spectra of equally prepared model surfaces were recorded in both chambers). The first setup, a dedicated Omicron surface science apparatus, equipped with HREELS, XPS and STM was used to investigate the CVD process and the prepared layers on $\mathrm{Cu}(111)$ under various reductive, oxidative and annealing conditions. In due course, XPS and catalytic performance were tested on polycrystalline $\mathrm{Cu}$ foils in a second UHV chamber, equipped with XP/Auger spectroscopy, low-energy ion scattering and an attached high-pressure batch-reactor. Additionally, in situ XPS measurements were performed at the ISISS beamline of the BESSY II synchrotron in Berlin, Germany.

\subsection{UHV-chamber with batch reactor}

$\mathrm{Cu}$ foil sample preparation and characterization was performed in a combined preparation/analysis chamber with attached reaction cell, described in more detail elsewhere [19]. It exhibits a base pressure in the low $10^{-9} \mathrm{mbar}$ range. The sample is heated via a homebuilt e-bombardment setup. Electrons are ejected from a triple-filament emitter (operated with $30 \mathrm{~W}$ heating power) set to $-500 \mathrm{~V}$, while the sample is set to +300 . The electron impact heating power is then controlled via the filament emission current. For spectroscopic analysis, the chamber is equipped with a hemispherical electron and ion analyzer (Thermo Fisher Electron Alpha 110), a double anode X-ray gun (Mg/Al, XR 50, Specs) for XPS, an ion gun (Omicron 100) to produce $1 \mathrm{kV} \mathrm{He}{ }^{+}$Ions for ISS (ion scattering spectroscopy) and an electron beam gun (KPI EGPS-2017B) for Auger electron spectroscopy. Additionally, a mass spectrometer (Balzers) for residual gas analysis and an $\mathrm{Ar}^{+}$ion sputter gun for sample cleaning are attached. A three-way gas inlet allows to dose $\mathrm{O}_{2}$ (Messer, 5.0), $\mathrm{H}_{2}$ (Messer 5.0) or $\mathrm{O}_{2}$ depleted $\mathrm{Ar}$ (Messer Ar 5.0, via Supelpure ${ }^{\circledR}-\mathrm{O}$ Oxygen/Moisture trap) via leak valves into the chamber. 
All XPS spectra collected in this chamber were recorded using a non-monochromatized $\mathrm{Mg}$ $\mathrm{K}_{\alpha} \mathrm{X}$-ray radiation $(\mathrm{h} \nu=1253.6 \mathrm{eV})$ at $250 \mathrm{~W}$ and at the "magic angle" of $\alpha=54.74^{\circ}$ between radiation and the energy analyzer. The analyzer was operated using a constant pass energy of $20 \mathrm{eV}$.

For catalytic testing in the high-pressure cell, a long z-transfer rod allows fast and reliable transfer without exposure to air. The all-quartz-glass high-pressure (up to 1 bar) batch reactor is equipped with a gas chromatograph with either intermediate or continuous EID-MS detection to determine the exact gas composition at any point of reaction. Continuous partial pressure detection is performed via a capillary leak to the EID detector. The quartz-glass reactor with a total circulation volume of $296 \mathrm{ml}$ was designed to measure small reaction rates and selectivity patterns within a temperature range of room temperature up to $1300 \mathrm{~K}$. A circulation pump ensures a constant flow and gas intermixing and an attached gas-premixing unit allows to set arbitrary compositions of the attached gases (methanol, methane, deionized and degassed water, $\mathrm{O}_{2}, \mathrm{H}_{2}, \mathrm{CO}, \mathrm{CO}_{2}, \mathrm{Ar}$ and $\mathrm{He}$ ). The sample holder itself is entirely made of quartz glass to avoid background reactivity from hot metal parts and is designed for $20 \mathrm{~mm}$ $\mathrm{x} 18 \mathrm{~mm}$ metal foils.

A partial pressure of 8 mbar Argon added to all gas mixtures allows to correct for the thermal expansion due to the temperature increase and the simultaneous gas loss through the capillary leak for continuous MS detection. For partial pressure calculations, all base-line-correctedMS signals were calibrated using pure substances with quantitative consideration of fragmentation. For all catalytic experiments shown in this work, the following initial conditions for MSR were applied: 12 mbar Methanol, 24 mbar water, 8 mbar Argon and He added to 1 bar total pressure. After an equilibration time of $10 \mathrm{~min}$, a temperature ramp of 10 $\mathrm{K} \min ^{-1}$ up to $623 \mathrm{~K}$ was performed, followed by an isothermal period at $623 \mathrm{~K}$. As for mass and heat transport limitations, we refer to a thorough discussion of the catalytic setup in ref. [19]. 
All catalytic experiments were performed using a $20 \mathrm{~mm}$ x $18 \mathrm{~mm}$ ultra-clean $\mathrm{Cu}$ foil $(99.9999 \%$, Alfa Aesar) with a thickness of $0.125 \mathrm{~mm}$. For reference experiments a $0.127 \mathrm{~mm}$ $\mathrm{Zr}$ foil $(99.95 \%$, Alfa Aesar) was used. The foils were cleaned before loading to the UHV chamber in a water and an ethanol ultrasonic bath for $20 \mathrm{~min}$, respectively.

\subsection{Omicron UHV set-up}

The HREEL spectra (LK HREELS 5000), the STM images as well as the corresponding XP spectra were recorded in an Omicron analysis chamber with a base pressure of $5 \times 10^{-11}$ mbar. The experimental set-up was described in detail elsewhere [20, 21]. An attached preparation chamber was used for sample cleaning and sample preparation. It is equipped with an $\mathrm{Ar}^{+}$ sputtering gun and a gas manifold system. Sample heating for the CVD process was done resistively and the temperature controlled with a K-type (chromel-alumel) thermocouple.

For HREELS and STM, a $\mathrm{Cu}(111)$ single crystal was used because of suitable mounting on the sample holder in the Omicron setup and the better defined surface, resulting in higher intensity and better resolution in the HREEL spectra and STM images. XPS data were acquired using a non-monochromatized $\mathrm{MgK} \alpha \mathrm{X}$-ray source $(\mathrm{h} v=1253.6 \mathrm{eV})$ at $150 \mathrm{~W}$. High resolution spectra were recorded at the constant pass energy of $20 \mathrm{eV}$ and a photoelectron ejection angle of $45^{\circ}$ (with respect to the surface normal).

\subsection{In situ Instrument}

Synchrotron-based in situ XPS experiments were performed at the ISISS (Innovative Station for In Situ Spectroscopy) beamline at the BESSY II synchrotron in Berlin, Germany. The experimental apparatus consists of a load lock and in situ cell connected to the photoemission spectrometer via differential pumping stages. It has been described in the literature 
extensively [22]. Samples were heated in the in situ cell via a near-infrared semiconductor laser $(\lambda=808 \mathrm{~nm})$ from the rear. Temperature was measured by a K-type (chromel-alumel) thermocouple positioned between sample holder back plate and $\mathrm{Cu}$ foil. All in situ experiments were performed on the same ultra-pure $\mathrm{Cu}$ foil that was used for the model catalyst preparations in the UHV instrument with attached batch reactor (see section 2.1). Also, the same ZTB cylinder/ leak valve setup was transferred to ISISS beamline. Due to the fact that ZTB only interacts with surfaces hotter than $500 \mathrm{~K}$, it was safe to dose the organometallic precursor into the analysis chamber without any $\mathrm{Zr}$ deposition on the components of the vacuum system or on the x-ray window. The growth of ZTB could then be followed in situ via XPS.

In order to extract information from a constant depth, photon energies were chosen (via the monochromator control) to have a kinetic energy of the emitted photoelectrons of $\sim 120 \mathrm{eV}$ for all monitored core-level photoemission peaks. Due to the fact that $\sim 95 \%$ of the signal arises from a sample depth up to $\sim 1 \mathrm{~nm}$ (electron attenuation length is $\sim 0.37 \mathrm{~nm}$ at $120 \mathrm{eV}$ for $\mathrm{Cu}$ $2 p_{3 / 2}$ in copper [23]), this operation mode is called "surface sensitive".

Photoelectrons were collected in the normal direction to the surface at constant pass energy of $10 \mathrm{eV}$. Binding energies were referenced to the Fermi edge, which was measured each time the monochromator settings changed (i.e. whenever the incident photon energy was changed). Photoemission peak intensities were corrected for the photon flux at a given photon energy. Since the BESSY II synchrotron operates in top-off mode (constant ring current), no correction for the ring current was required. Since all photoemission peaks were collected at the same kinetic energy of photoelectrons $(120 \mathrm{eV})$, the attenuation through the gas phase was the same for all core-levels and thus cancels out in coverage calculations.

\subsection{Sample Preparation}


Before $\mathrm{Zr}$ deposition, the samples were cleaned carefully via several cycles of $\mathrm{Ar}^{+}$ sputtering/annealing and the purity checked by XPS, in case of the Omicron setup by STM as well. All possible impurities were below the XPS detection limit for all prepared model catalysts.

Exposure to the CVD precursor (ZTB) was performed in the preparation chamber for the Omicron set-up and in the combined preparation/analysis chamber for the UHV-chamber with attached batch reactor. In the in situ measurements, the ZTB was dosed during XPS measurements.

For the CVD process, the sample was heated up to 573-773 K (note the different sample heatings for the three systems). An ultra-clean $\mathrm{Cu}$ foil $(99,999 \%)$ and accordingly, a $\mathrm{Cu}(111)$ single crystal (for the Omicron setup) were exposed to the volatile organometallic precursor at different template temperatures. Zirconium(IV)-tert-butoxide (Sigma Aldrich, purity. $99.999 \%$, for Omicron instrument: Strem, purity: 99\%) was contained in a stainless steel cylinder and purified by several cycles of freeze-pump-thaw. It was then dosed under strict control of the sample temperature into the preparation chamber via a leak valve. The amount of dosing was varied between $100 \mathrm{~L}\left(3.3 \times 10^{-7}\right.$ mbar for $\left.400 \mathrm{~s}\right)$ and $2000 \mathrm{~L}\left(6.6 \times 10^{-6} \mathrm{mbar}\right.$ ZTB for $420 \mathrm{~s}$ ). However, since the actual deposited film thickness highly depends on the sample temperature/pre-conditioning of the chamber walls, this value should be rather viewed as a rough estimate. For a much more accurate quantification of the deposited material, the film thickness and the surface coverage were calculated using Fadley's approach namely an attenuated overlayer model and a non-attenuated model, correspondently [24, 25]. The approach are described in the Supplementary Information. The $\mathrm{Cu} / \mathrm{ZrO}_{\mathrm{x}}$ surface ratio determined by LEIS allowed to subsequently establish a correlation between catalytic performance and the abundance of the $\mathrm{ZrO}_{\mathrm{x}} \mathrm{H}_{\mathrm{y}} / \mathrm{Cu}$ interface. 
All spectra were analyzed using the CasaXPS software, version 2.3.16 Pre-rel 1.4 (Casa Software Ltd.) [26]. The area under a photoemission peak was measured after a Shirley background subtraction and was corrected for the associated Scofield relative sensitivity factors. For peak fitting of the $\mathrm{Zr} 3 \mathrm{~d}$ peaks a weighted sum of Gaussian and Lorenzian peak shapes (CasaXPS line shape SGL(30)) was used. A fixed spin-orbital splitting doublet separation ( $\mathrm{Zr} \mathrm{3d_{5/2 }}$ vs. $\mathrm{Zr} \mathrm{3d_{3/2 }}$ ) of $2.4 \mathrm{eV}$ for both metallic $\mathrm{Zr}$ [27] and zirconia [28] was used. The doublet area was constrained to be 3:2 as arising from spin-orbit splitting for delectrons. Electron attenuation lengths were taken from the NIST database SR 82 [23] and the orbital asymmetric parameters from the ELETTRA online database of ref. [29] (cancelled out for the "magic" angle). The surface coverage was estimated by a non-attenuated overlayer model on a semi-infinite substrate for fractional coverages [25]. For thickness estimations, a model that considers photoelectron attenuation through the substrate and the overlayer was used. While the coverage estimation is more meaningful for sub-monolayer overlayer, a multi-monolayer film can be more accurately described by the attenuating overlayer model. For low thicknesses, the influence of the attenuation effect is low and therefore the results of both models (coverage in ML and thickness in $\AA$ ) are convertible under consideration of the chemical composition of the overlayer. Details of these calculations are given in the Supplementary Information in Section A. For in situ XPS data, a photon flux was normalized for different photon energies. 


\section{Results and Discussion}

\section{A. $\mathrm{ZrO}_{x} \mathrm{H}_{y}$ layer growth by $\mathrm{CVD}$ on $\mathrm{Cu}$}

\section{A.1. Deposition of the layers}

For deposition of $\mathrm{ZrO}_{\mathrm{x}} \mathrm{H}_{\mathrm{y}}$ layers of $\mathrm{ZTB}$ on $\mathrm{Cu}$, similar activation barriers appear as documented for e.g. ZTB on $\mathrm{Si}[30,31]$. A minimum temperature of around $573 \mathrm{~K}$ is required to observe any $\mathrm{Zr}$ on the surface. The $\mathrm{Zr}$ coverage increases with increasing sample temperature (and, at a given temperature, with the exposure in Langmuir). Finally reaches a maximum at around $693 \mathrm{~K}$. At higher exposure temperatures, for a given exposure, the $\mathrm{Zr}$ coverage decreases and reaches zero above around $823 \mathrm{~K}$. The ratio between $\mathrm{C}$ and $\mathrm{Zr}$ is highly influenced by the exposure temperature, but in all cases lower than $16 \mathrm{C}$ atoms per $\mathrm{Zr}$ (referenced to the precursor). The carbon coverage is comparably low for the optimum temperature of $693 \mathrm{~K}$. Therefore, this temperature was chosen for preparation of the $\mathrm{Zr}$ overlayers for catalytic experiments (for details see below). In contrast, at the minimum temperature of $573 \mathrm{~K}$, a relatively high carbon coverage was found. Carbon coverages can be reduced by post-annealing treatments and approach zero at approximately $973 \mathrm{~K}$. Despite the fact that the $\mathrm{Zr} / \mathrm{O}$ ratio was hardly affected, annealing has a considerable effect on the prepared $\mathrm{ZrO}_{\mathrm{x}} \mathrm{H}_{\mathrm{y}}$ layer (section 3.A.2 and 3.A.3). 


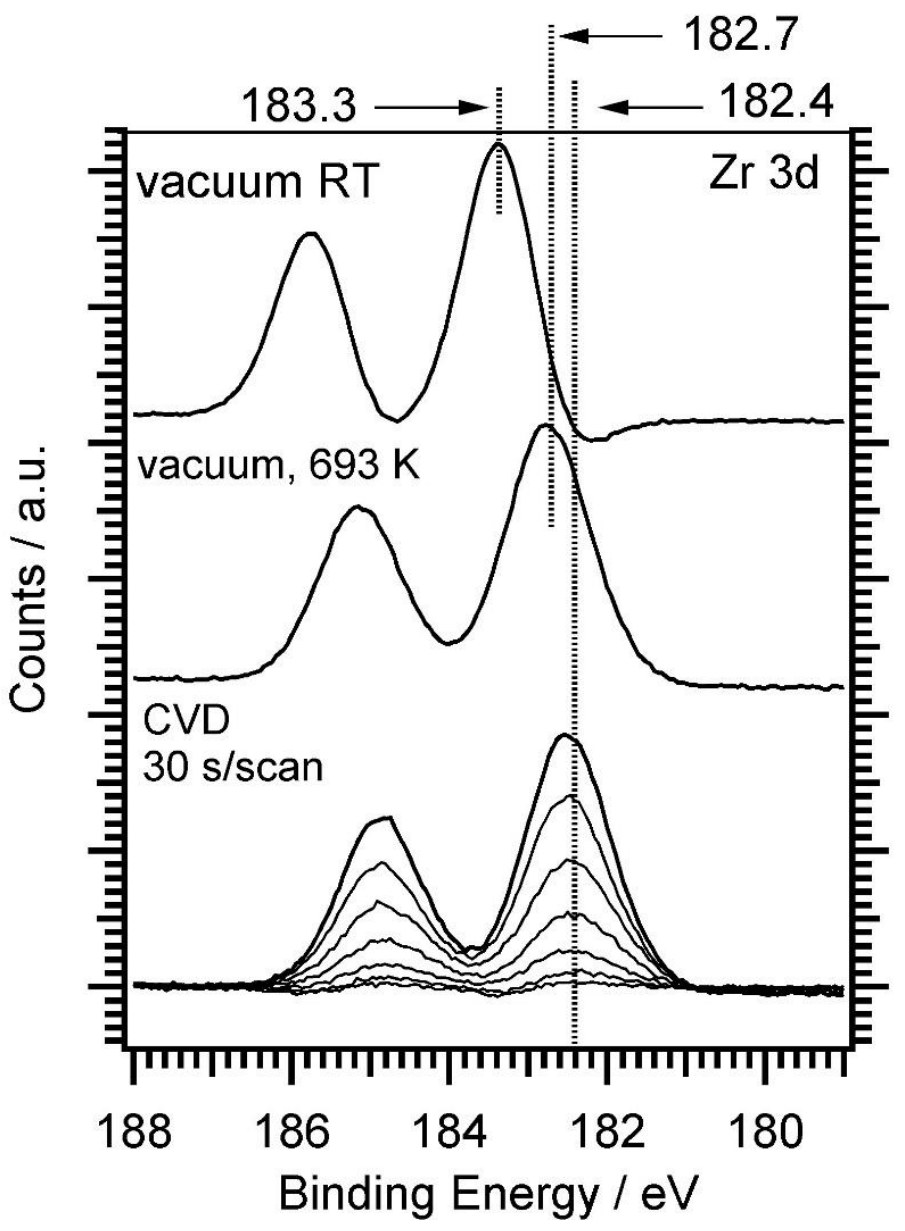

Figure 1: Core-level $\mathrm{Zr} 3 \mathrm{~d}$ spectra obtained (i) in situ during the growth of a $\mathrm{ZrO}_{\mathrm{x}} \mathrm{H}_{\mathrm{y}}$ overlayer on a polycrystalline $\mathrm{Cu}$ foil at $693 \mathrm{~K}$ in $5 \times 10^{-6}$ mbar ZTB (bottom set of the spectra), (ii) after ZTB pumping in vacuum at $693 \mathrm{~K}$ (middle spectrum) and (iii) at RT (top spectrum).

The prepared overlayer was further investigated by XPS and HREELS. To ensure direct comparison with the layer subsequently used for the catalytic experiments, the discussion of the spectra is restricted to the overlayer prepared at $693 \mathrm{~K}$. This was also the temperature for the catalyst preparation due to the lowest $\mathrm{C}$ content and efficient $\mathrm{Zr}$ deposition. Figure 1 shows the in situ spectra during exposure of $5 \times 10^{-6}$ mbar ZTB at $693 \mathrm{~K}$ (acquisition time for each spectrum $30 \mathrm{~s}$ ). Note that a possible influence of the synchrotron X-ray on the 
decomposition mechanism cannot be ruled out. During in situ ZTB exposure, the peak maxima of the $\mathrm{Zr} 3 \mathrm{~d}_{5 / 2}$ state do not shift considerably. However, the $\mathrm{Zr} 3 \mathrm{~d}_{3 / 2}$ peak shifts by $\sim 0.9 \mathrm{eV}$ (up to $183.3 \mathrm{eV}$ ) if ZTB was pumped off and the sample was cooled to RT. A detailed structural discussion, including the finding that the formed overlayer prefers a $2 \mathrm{ML}$ thickness as distinguished from combined XPS and LEIS results and substantiated by DFT, can be found in section 3.C. and Figure S3.

As for the chemical state of the $\mathrm{ZrO}_{\mathrm{x}} \mathrm{H}_{\mathrm{y}}$ overlayer, ex situ collected $\mathrm{Zr} 3 \mathrm{~d}_{3 / 2}$ XPS peaks (Figure 2, "as grown") show an up-shift from the $\mathrm{Zr}^{+4}\left(\mathrm{ZrO}_{2}\right)$ state at $182.3 \mathrm{eV}$ to $183.1 \mathrm{eV}$ due to (partial) hydroxylation $\left(\mathrm{Zr}-(\mathrm{OH})_{4} \mathrm{BE}\right.$ at $183.1 \mathrm{eV}$ [32]). This shift correlates with the one observed for $\mathrm{O}$ 1s spectra: the $\mathrm{O}$ 1s peak is found at around $1 \mathrm{eV}$ above the $\mathrm{ZrO}_{2}$ position $(\sim 530.4 \mathrm{eV})$. Peak fitting in the $\mathrm{O} 1 \mathrm{~s}$ region was not performed because of the fact that more compounds (i.e. carbon oxygenates) contributed to this region and an unambiguous peak fit can therefore not be performed. However, the trend in peak position is clear and is directly proven by additional HREEL spectra (cf. Figure 4, right panel c, "precursor state"; vibrational mode above $3650 \mathrm{~cm}^{-1}$ indicating the presence of $\mathrm{Zr}-\mathrm{OH}$ groups already in the as grown films). The position of the carbon peak in the $\mathrm{C} 1 \mathrm{~s}$ spectra at $284.4-284.6 \mathrm{eV}$ is characteristic for $\mathrm{sp}^{3}$-hybridized carbon in $\mathrm{C}-\mathrm{C}$ and $\mathrm{C}-\mathrm{H}$ entities. 


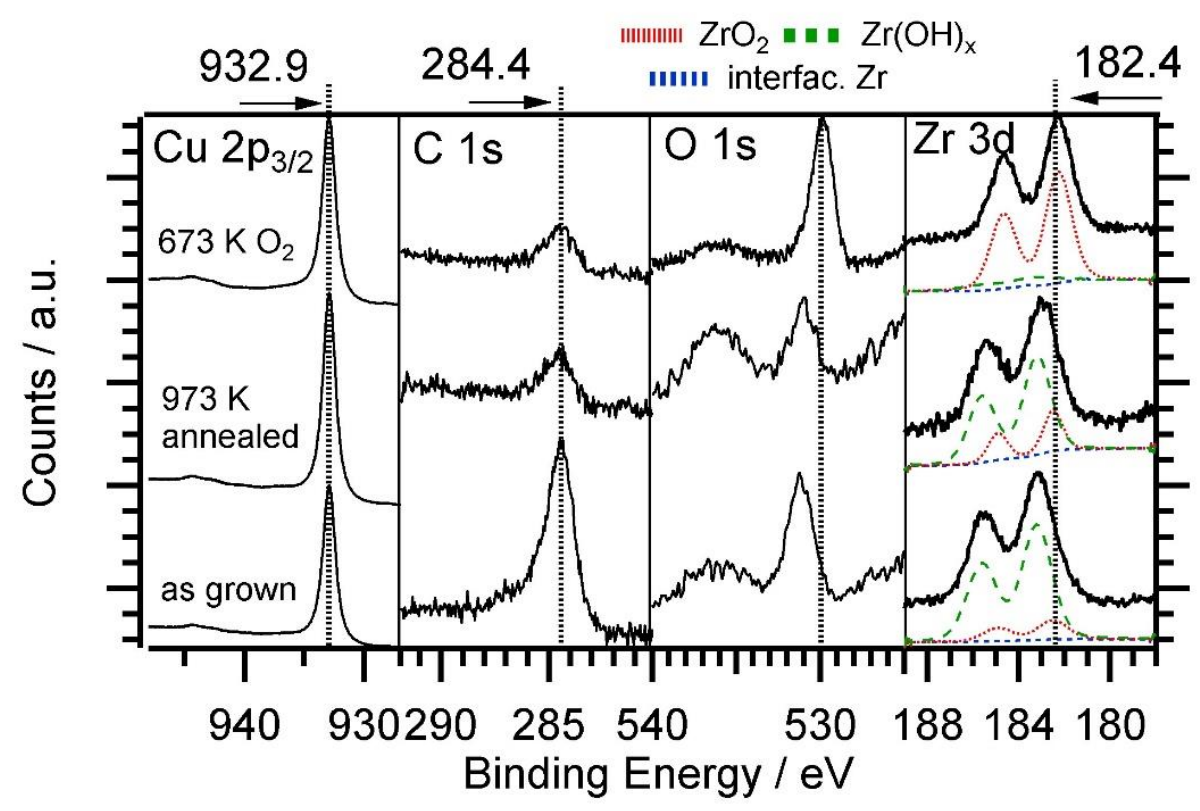

Figure 2: XP spectra collected on a $\mathrm{Cu}(111)$ single crystal exposed at $693 \mathrm{~K}$ to obtain $0.1 \mathrm{ML}$ ZTB. Starting from a freshly prepared sample, marked as "as grown", vacuum annealing at $973 \mathrm{~K}$ was done first and then $\mathrm{O}_{2}$ oxidation was performed. $\mathrm{Cu} 2 \mathrm{p}_{3 / 2}, \mathrm{C} 1 \mathrm{~s}, \mathrm{O}$ 1s and $\mathrm{Zr} 3 \mathrm{~d}$ peaks are shown in separate sub-panels.

\section{A.2. High-temperature annealing}

In vacuo and oxidative post-annealing of the as-prepared films in $5 \times 10^{-7}$ mbar $\mathrm{O}_{2}$ (by backfilling the UHV chamber) have been performed to better understand the transformation of the layers also during the catalytic reactions. These "reference" spectra were then used to assign the corresponding $\mathrm{Zr}$ chemical states. Moreover, post-treatment experiments on the $\mathrm{Cu}(111)$ single crystal performed by XPS, HREELS and STM were also used to correlate the observed $\mathrm{Zr}$ oxidation states after catalytic MSR treatments on $\mathrm{Cu}$ foils. Figure 2 shows these XP spectra obtained from the CVD as-grown $\mathrm{ZrO}_{\mathrm{x}} \mathrm{H}_{\mathrm{y}}$ overlayers on a $\mathrm{Cu}(111)$ single crystal, after $973 \mathrm{~K}$ vacuum annealing and subsequent $\mathrm{O}_{2}$ annealing at $673 \mathrm{~K}$. The as-grown state consists of (partially) hydroxylated $\mathrm{ZrO}_{\mathrm{x}} \mathrm{H}_{\mathrm{y}}$, as deduced from the shift of the $\mathrm{O}$ 1s binding 
energy as well as from the $\mathrm{Zr} 3 \mathrm{~d}_{3 / 2}$ peak position at $183.2 \mathrm{eV}$ and the corresponding HREEL spectra of the "precursors state" in Figure 4.

Vacuum annealing at $973 \mathrm{~K}$ causes minor changes (slight loss of $\mathrm{Zr}-\mathrm{OH}$ indicated by a shift of the $\mathrm{Zr} 3 \mathrm{~d}$ signal towards lower binding energies), as well as a broadening of the $\mathrm{O} 1 \mathrm{~s}$ peaks due to the presence of a second state, namely $\mathrm{ZrO}_{2}$, at $530.4 \mathrm{eV}$. The feature at $\sim 535 \mathrm{eV}$ in the $\mathrm{O}$ 1s region is a $\mathrm{Cu}$ LMM Auger line. The apparent intensity increase in Figure 2 (973 K annealing) arises from a lower $\mathrm{O} 1 \mathrm{~s}$ intensity. The relative intensity of the $\mathrm{Cu}$ LMM Auger line related to the $\mathrm{Cu} 2 \mathrm{p}_{3 / 2}$ photoemission line is approximately (not exact due to different attenuations) constant for all three shown spectra of Figure 2. The vacuum-annealed state now is clearly a mixture of both, $\mathrm{ZrO}_{2}$ and $\mathrm{Zr}(\mathrm{OH})_{4}$, and probably also intermediate species such as $\mathrm{ZrO}_{\mathrm{x}}(\mathrm{OH})_{4-2 \mathrm{x}}$. The incomplete loss of hydroxylated $\mathrm{Zr}$ with annealing at $900 \mathrm{~K}$ of an CVDprepared layer using ZTB on $\mathrm{Si}(111)$ was also found by Cameron et all [31].

Treatment in $\mathrm{O}_{2}(673 \mathrm{~K})$ leads to fully oxidized $\mathrm{ZrO}_{2}$ with a $\mathrm{Zr}$ 3d BE consistent with literature values $(182.4 \mathrm{eV})$. From the spectra shown in Figure 2 it becomes clear that annealing at $973 \mathrm{~K}$ is an effective way of carbon removal. Only a small peak in the $\mathrm{C} 1 \mathrm{~s}$ region persists, which cannot be removed in oxygen. Only by performing oxidative pretreatments before annealing at $973 \mathrm{~K}$, carbon can be removed completely (cf. Figure 3).

\section{A.3 Reductive treatments}

The motivation to carry out reductive treatments of the CVD-prepared films is mainly fueled by previous experiments on sputter-prepared "inverse" (i.e. $\mathrm{ZrO}_{\mathrm{x}}$-on-Cu) catalysts, which showed a high $\mathrm{CO}_{2}$-selectivity in methanol steam reforming, if the pre-catalyst contained a $\mathrm{Zr}$ metal component [15]. In order to obtain comparable CVD-based pre-catalyst states, reductive treatments have been carried out. As summarized in Table 1, different reductive posttreatments of the prepared film do neither affect the position of the $\mathrm{Zr} 3 \mathrm{~d}$ peak nor the $\mathrm{O}$ quantity (spectra are not shown because of qualitative similarities). This is also true upon 
applying very harsh reduction conditions as e.g. in $14 \mathrm{~W}$ cold hydrogen plasma. Already hydroxylated $\mathrm{Zr}$ remains hydroxylated and is apparently very stable, indicating that the $\mathrm{Zr}-\mathrm{O}$ bond cannot be cracked. Table 1 lists the treatment conditions and the associated $\mathrm{Zr} 3 \mathrm{~d}_{5 / 2}$ binding energies for various reductive treatments. A binding energy shifted to $183.0-183.1 \mathrm{eV}$ is characteristic for hydroxylated $\mathrm{Zr}$. Upon $\mathrm{H}^{+}$sputtering, the ion gun designated for $\mathrm{Ar}^{+}$ sputtering for sample cleaning was operated with a hydrogen background pressure of $1 \times 10^{-4}$ mbar (ion energy $1 \mathrm{keV}$, ion current $\sim 3 \mu \mathrm{A}$ ). As no shift is observed in the $\mathrm{Zr} 3 \mathrm{~d}$ binding energy, no $\mathrm{Zr}$ reduction takes place.

Table 1: Summary of reduction treatments of the as grown films, with $\mathrm{Zr}$ coverages obtained from the XPS overlayer model (see section 2.4.) and associated $\mathrm{Zr} 3 \mathrm{~d}$ peak positions.

\begin{tabular}{|c|c|c|c|c|}
\hline Substrate & Exposure & $\mathrm{Zr}$ cov. / ML & Reductive Treatment & $\mathrm{Zr} 3 \mathrm{~d}_{5 / 2} \mathrm{BE} / \mathrm{eV}$ \\
\hline $\mathrm{Cu}(111)$ & $\sim 2000 \mathrm{~L} \mathrm{ZTB}$ & 0.06 & $5 \times 10^{-6}$ mbar H2, $673 \mathrm{~K}, 15 \mathrm{~min}$ & 183.1 \\
\hline $\mathrm{Cu}(111)$ & $\sim 2000 \mathrm{~L}$ ZTB & 0.04 & $5 \times 10^{-6} \mathrm{mbar} \mathrm{H} 2,873 \mathrm{~K}, 15 \mathrm{~min}$ & 183.1 \\
\hline $\mathrm{Cu}(111)$ & 2000L ZTB & 0.14 & H-plasma $(14 \mathrm{~W}), 10 \mathrm{~min}$ & 183.1 \\
\hline $\mathrm{Cu}(111)$ & $\sim 2000 \mathrm{~L}$ ZTB & 0.06 & $\mathrm{H}^{+}$-sputtering, $5 \mathrm{~min}$ & 183.0 \\
\hline
\end{tabular}

\section{A.4. Oxidative treatments}

Similar to the reductive treatments, also oxidative treatments of $\mathrm{ZrO}_{\mathrm{x}}$ on $\mathrm{Cu}$ systems have been observed to have a direct impact on the catalytic properties. For best appreciating the depth of interpretation, Figure 3 (XPS results) and Figure 4 (HREELS data) are jointly discussed. As shown in Table 2 and Figure 3, treatments in oxygen (besides effective carbon removal) induces a corresponding $\mathrm{Zr} 3 \mathrm{~d}$ binding energy shift to lower BE's, even lower as compared to the literature position of $\mathrm{ZrO}_{2}$ [33]. The $\mathrm{Cu} 2 \mathrm{p}_{3 / 2}, \mathrm{O}$ 1s and $\mathrm{Zr} 3 \mathrm{~d}$ binding energies are jointly listed in Table 2 . The $\mathrm{Zr} 3 \mathrm{~d}_{3 / 2}$ peak shift is interpreted mainly in terms of the loss of hydroxyl groups. However, the HREEL spectra still indicate the presence of $\mathrm{Zr}$ $\mathrm{OH}$ (cf. Figure 4, panel b, “ $\mathrm{O}_{2}$ treatment”). Also the intensity of the $\mathrm{Zr}-\mathrm{O}$ vibrations between 493 and $700 \mathrm{~cm}^{-1}$ increase with oxidative treatment, indicating a carbon clean-off reaction. 
The effect results in higher intensity of the of $\mathrm{ZrO}_{x} \mathrm{H}_{y}$ species and explains why the $\mathrm{Zr}-\mathrm{OH}$ peak at $3673 \mathrm{~cm}^{-1}$ even slightly increases. With the HREEL spectra in mind, special care needs to be applied upon interpretation of the observed binding energy shifts. The downward shift of the $\mathrm{Zr} 3 \mathrm{~d}$ peak from $\sim 183.0 \mathrm{eV}$ to $182.0 \mathrm{eV}$ could be interpreted as dehydroxylation. However, for the formation of oxidized surface species (by oxygen treatment) many other effects such as partial shape effect, delayed charge transfer from the substrate or charging, mostly likely even a combination of these effects, may contribute to the peak position. The relevance of such phenomena is also corroborated by the fact that the $\mathrm{O} 1 \mathrm{~s} \mathrm{BE}$ and $\mathrm{Zr} 3 \mathrm{~d} \mathrm{BE}$ shift are up to a certain extent parallel. This situation makes the chemical shift rather unspecified to the actual binding character of $\mathrm{Zr}$ and therefore hard to interpret.

According to HREELS, upon consideration of the carbon clean-off effect, the $\mathrm{Zr}-\mathrm{OH}$ signal at $3673 \mathrm{~cm}^{-1}$ was normalized to the $\mathrm{Zr}-\mathrm{O}$ vibration at $692 \mathrm{~cm}^{-1}$ with the result that $73 \%$ of initial $\mathrm{Zr}-\mathrm{OH}$ groups remain after $\mathrm{O}_{2}$ treatment. This downshift in binding energy with $\mathrm{O}_{2}$ treatment is directly correlated with an activity decrease in methanol steam reforming as discussed in detail in the catalytic section. After high-temperature annealing, the oxygen-induced low binding energy shift is restored and approaches literature values for $\mathrm{Zr} 3 \mathrm{~d}$ and $\mathrm{O}$ 1s in fully oxidized $\mathrm{ZrO}_{2}$. 


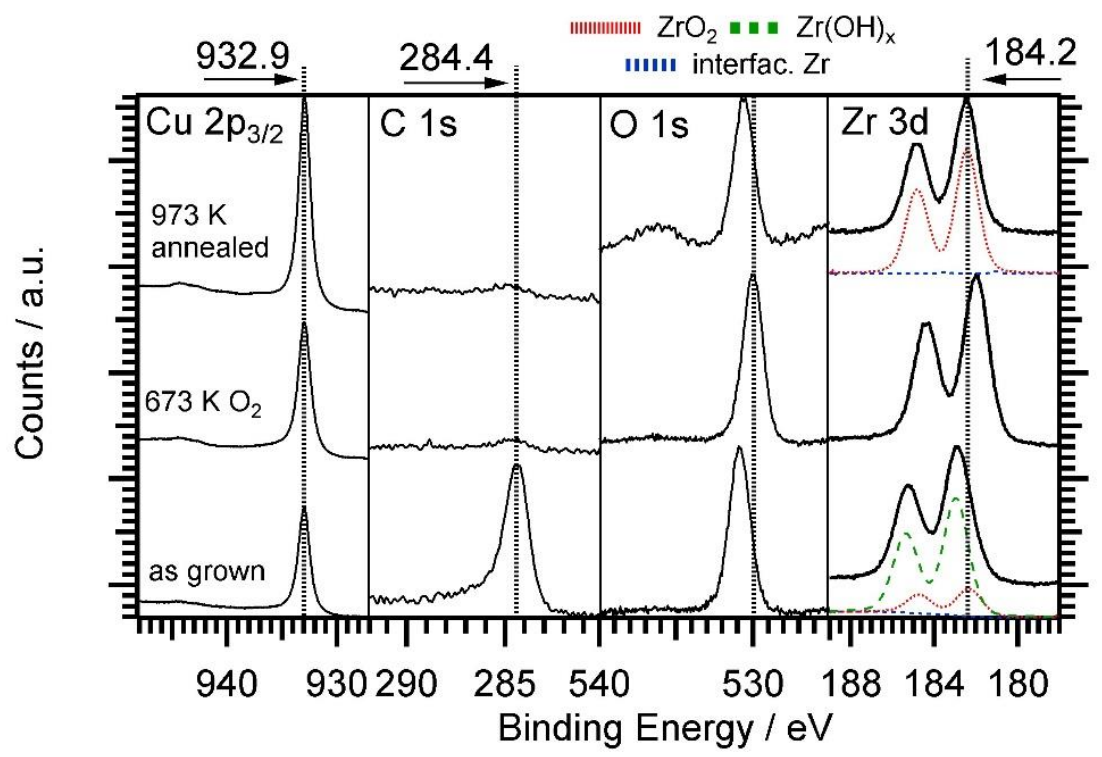

Figure 3: XP spectra collected on a $\mathrm{Cu}(111)$ single crystal covered with 0.6 ML ZTB. Starting from a freshly at $693 \mathrm{~K}$ exposed sample, marked as "as grown", oxidation and annealing was performed (reverse order to Figure 2). $\mathrm{Cu} 2 \mathrm{p}_{3 / 2}, \mathrm{C} 1 \mathrm{~s}, \mathrm{O} 1 \mathrm{~s}$ and $\mathrm{Zr} 3 \mathrm{~d}$ peaks are shown in separate sub-panels.

With corresponding annealing of the oxidized sample in vacuum at $973 \mathrm{~K}$, a total loss of $\mathrm{Zr}$ OH was found in HREEL spectra (Figure 4, panel a: "973 K annealed"), complemented by a Zr 3d binding energy shift to higher values in the XP spectra (Figure 3). This shift indicates partial reversal of the $\mathrm{O}_{2}$ - induced low $\mathrm{BE}$ shift. The $\mathrm{Zr} 3 \mathrm{~d}$ peak position at $182.4 \mathrm{eV}$ after the vacuum annealing is perfectly in line with listed literature value for bulk $\mathrm{ZrO}_{2}$ [33]. STM images (shown in the SI in Figure S1) indicate hexagonal holes within an otherwise flat $\mathrm{Cu}$ surface, which is in correlation with the increase of the $\mathrm{Cu} 2 \mathrm{p}_{3 / 2}$ peak intensity in XPS (Figure 3). This interpretation is also substantiated by the significant loss of $\mathrm{Zr}-\mathrm{O}$ vibrations around $700 \mathrm{~cm}^{-1}$ due to the loss of surface $\mathrm{Zr}$-species.

Oxidative annealing treatments of the as-grown CVD film using $\mathrm{H}_{2} \mathrm{O}\left(5 \times 10^{-7}\right.$ mbar $\mathrm{H}_{2} \mathrm{O}$ at $696 \mathrm{~K}$ ) causes no shift and no intensity change in neither the $\mathrm{Zr} \mathrm{3d}, \mathrm{C} 1 \mathrm{~s}$, O 1s nor the $\mathrm{Cu}$ $2 \mathrm{p}_{3 / 2}$ region (corresponding binding energies listed in Table 2, spectra shown in SI) and no 
changes in the HREEL spectra. This indicates saturation of hydroxylation of $\mathrm{Zr}$ is reached even before treatment with water and/or that additional heterolytic water splitting on the already existing $\mathrm{ZrO}_{x} \mathrm{H}_{y}$ species is kinetically hindered.

Table 2: Summary of oxidative treatments of the as-grown films in either $\mathrm{O}_{2}$ or $\mathrm{H}_{2} \mathrm{O}$, with associated $\mathrm{Cu} 2 \mathrm{p}_{3 / 2}, \mathrm{C} 1 \mathrm{~s}, \mathrm{O} 1 \mathrm{~s}$ and $\mathrm{Zr} 3 \mathrm{~d}$ peak positions. The corresponding spectra are shown in the SI.

\begin{tabular}{|l|c|c|c|c|}
\hline $\begin{array}{l}\text { Treatment } \\
\text { CVD followed by }\end{array}$ & $\begin{array}{c}\mathrm{BE} \mathrm{Cu} 2 \mathrm{p}_{3 / 2} \\
/ \mathrm{eV}\end{array}$ & $\begin{array}{c}\mathrm{BE} \mathrm{C} \mathrm{1s} \\
/ \mathrm{eV}\end{array}$ & $\begin{array}{c}\mathrm{BE} \mathrm{O} \mathrm{1s} \\
/ \mathrm{eV}\end{array}$ & $\begin{array}{c}\mathrm{BE} \mathrm{Zr} \mathrm{3d} \\
/ \mathrm{eV}\end{array}$ \\
\hline $5 \times 10^{-7} \mathrm{mbar}_{2}, 15 \mathrm{~min}, 673 \mathrm{~K}$ & 932.9 & - & 530.0 & 182.0 \\
\hline $5 \times 10^{-7} \mathrm{mbar}_{2}, 15 \mathrm{~min}+973 \mathrm{~K}$ vacuum annealed & 932.9 & - & 530.6 & 182.4 \\
\hline $5 \times 10^{-7} \mathrm{mbar} \mathrm{H}_{2} \mathrm{O}, 15 \mathrm{~min}, 673 \mathrm{~K}$ & 932.9 & 284.5 & 530.9 & 182.9 \\
\hline
\end{tabular}

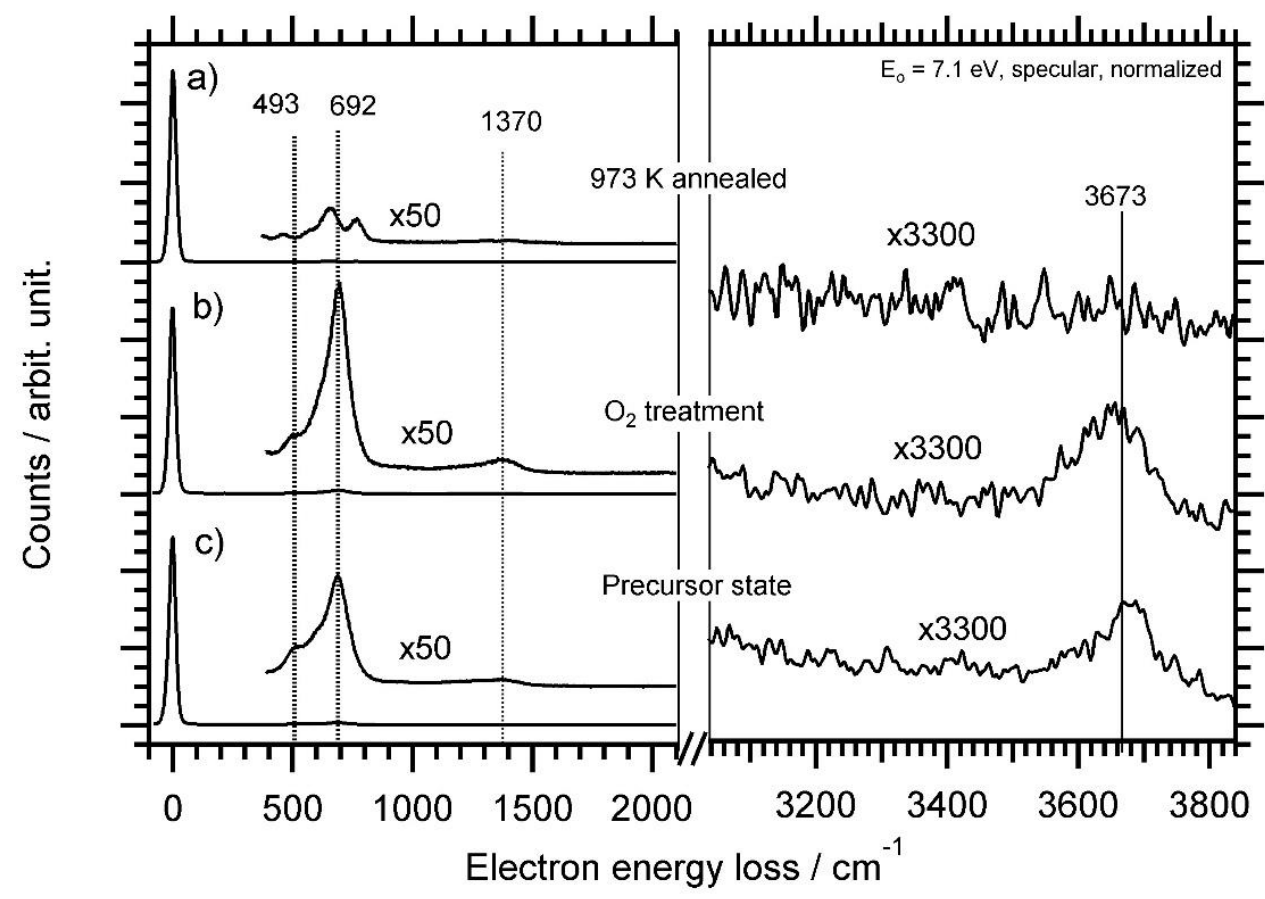

Figure 4: HREEL spectra of the as-grown CVD-prepared $\mathrm{ZrO}_{\mathrm{x}} \mathrm{H}_{\mathrm{y}}$ overlayer on $\mathrm{Cu}$ and two selected post-treatment experiments. Primary counts and FWHM: a) $2.21 \times 10^{5} \mathrm{cps} / 33 \mathrm{~cm}^{-1} \mathrm{~b}$ ) $\left.1.27 \times 10^{5} \mathrm{cps} / 32 \mathrm{~cm}^{-1} \mathrm{c}\right) 3.67 \times 10^{5} \mathrm{cps} / 33 \mathrm{~cm}^{-1}$. Cu-O vibrations due to partial oxidation of the substrate during reaction contribute in a minor way to the $\mathrm{Zr}-\mathrm{O}$ vibrations around $600 \mathrm{~cm}^{-1}$. A reference spectrum for $\mathrm{Cu}-\mathrm{O}$ can be found in the SI (Figure S2). 


\section{B. Catalytic measurements in methanol steam reforming}

\section{B.1.Pure Cu foil}

As there are some contradicting facts about the catalytic performance of pure $\mathrm{Cu}$ in MSR in literature $[34,35]$, the properties of the polycrystalline $\mathrm{Cu}$ foil used herein have been characterized in detail to identify solely Cu-related catalytic effects. Furthermore, they should allow a more detailed discussed of the catalytic activation of $\mathrm{Cu}$ via a sub-monolayer $\mathrm{ZrO}_{\mathrm{x}} \mathrm{H}_{\mathrm{y}}$ coverage in the used batch-reactor setup. The Cu-foil (Alpha Aesar, $99.9999 \%$ purity) was UHV-cleaned via several cycles of sputtering/annealing until only $\mathrm{Cu}$ was seen in XPS. The reactivity pattern of the clean foil in MSR is shown in Figure 5, panel a). There is clear evidence that the ultra-pure $\mathrm{Cu}$ foil is not reactive at all in MSR in our batch reactor setup. Panel b) shows the MSR performance of the same sample after a preceding oxidative steam reforming experiment (OSR, same experimental protocol as for MSR, but 12 mbar methanol +24 mbar water +6 mbar $\left.\mathrm{O}_{2}\right)$. Cu is obviously activated to some extent by the $\mathrm{O}_{2}$ co-feed, but only toward formaldehyde formation $[4,5,16]$. However, both on pure $\mathrm{Cu}$ and $\mathrm{O}_{\text {sub- }}$ activated $\mathrm{Cu}$, no (quantitative) water activation is seen and therefore no $\mathrm{CO}_{2}$ is formed. In addition, full dehydrogenation on $\mathrm{Cu}$ is also not accessible as indicated by the inexistent $\mathrm{CO}$ formation. Therefore, only the first steps in MSR, the activation of methanol to create weakly surface bound methoxy $\left(-\mathrm{O}-\mathrm{CH}_{3}\right)$ species, which then become selectively dehydrogenated toward formaldehyde, take place, followed by formaldehyde desorption. A similar behavior can be seen for a polycrystalline $\mathrm{Cu}$ foil with lower purity (99.95\%, Goodfellow). This MSR experiment is shown in Panel $\mathrm{C}$ of Figure 5. Formaldehyde is the main product, but before complete deactivation takes place, also $\mathrm{CO}_{2}$ as a minority component is formed. Most likely, trace impurities on the surface allow for measurable water activation and, thus, total oxidation toward $\mathrm{CO}_{2}$. Nevertheless, full dehydrogenation to $\mathrm{CO}$ is absent in the reactivity pattern. 


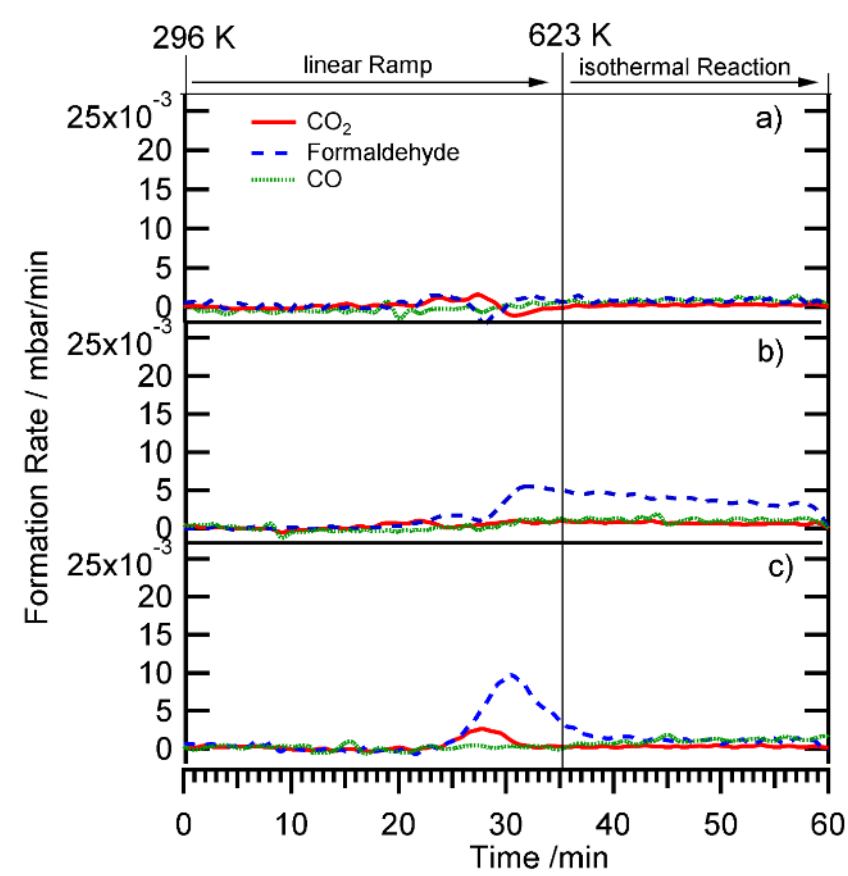

Figure 5: MSR reactivity for different polycrystalline $\mathrm{Cu}$ foils: a) clean, $99.9999 \%$ purity, b) $\mathrm{O}_{2}$ exposed via preceding OSR, $99.9999 \%$ purity, c) clean, lower nominal purity: $99.95 \%$. Reaction conditions: 12 mbar methanol, 24 mbar water, 8 mbar Argon and He added to 1 bar total pressure. After an equilibration time of $10 \mathrm{~min}$, a temperature ramp of $10 \mathrm{~K} \mathrm{~min}^{-1}$ up to $623 \mathrm{~K}$ was performed, followed by an isothermal period at $623 \mathrm{~K}$.

\section{B.2. CVD-prepared $\mathrm{ZrO}_{x} \mathrm{H}_{y}$ on $\mathrm{Cu}$ foil}

In Figure 6, the selectivity patterns/ activities of pure $\mathrm{Cu}(\mathrm{a})$, pure $\mathrm{ZrO}_{2}(\mathrm{~d})$ and two samples of $\mathrm{ZrO}_{\mathrm{x}} \mathrm{H}_{\mathrm{y}}$ (b,c) are shown. Onset of product formation was observed between 580 and $600 \mathrm{~K}$. For the lowest $\mathrm{ZrO}_{\mathrm{x}} \mathrm{H}_{\mathrm{y}}$ coverage, the catalyst is highly formaldehyde-selective. However, with increasing coverage pathways to $\mathrm{CO}$ and $\mathrm{CO}_{2}$ get accessible, but are not very effective as the rate maxima of the latter remain below the formaldehyde maximum. Figure 7 in turn shows the plot of reaction rate versus $\mathrm{ZrO}_{\mathrm{x}} \mathrm{H}_{\mathrm{y}}$ coverage for all studied $\mathrm{ZrO}_{\mathrm{x}} \mathrm{H}_{\mathrm{y}} / \mathrm{Cu}$ samples. Table 3 sums up all reaction rate maxima and the corresponding turnover frequencies for the seven tested samples. The total number of "free" surface $\mathrm{Cu}$ sites was calculated from the substrate 
area under consideration of the ratio of free $\mathrm{Cu}$ surface from ISS (Figure S4) and an average surface atom density of $1.65 \times 10^{15} \mathrm{Cu}$ atoms $/ \mathrm{cm}^{2}$ (average of (111) and (100) surface).

Table 3: Reaction rates and estimated turnover frequencies for the five $\mathrm{ZrO}_{\mathrm{x}} \mathrm{H}_{\mathrm{y}} / \mathrm{Cu}$ samples and the pure $\mathrm{Cu}$ and $\mathrm{ZrO}_{2}$ reference catalysts.

\begin{tabular}{|c|c|c|c|c|c|c|c|c|}
\hline \multirow[t]{2}{*}{$\begin{array}{l}\text { Sample } \\
\text { No. }\end{array}$} & \multirow[t]{2}{*}{ Sample Descriptor } & \multirow{2}{*}{$\begin{array}{l}\text { Estimated } \\
\text { number of } \\
\text { surface } \mathrm{Cu} \\
\text { sites }\end{array}$} & \multicolumn{3}{|c|}{$\begin{array}{l}\text { Maximum formation rate } / \\
10^{-3} \mathrm{mbar} \mathrm{min}^{-1}\end{array}$} & \multicolumn{3}{|c|}{$\begin{array}{l}\text { Maximum turn over } \\
\text { frequency based on } \\
\text { surface } \mathrm{Cu} \text { sites } / \mathrm{s}^{-1}\end{array}$} \\
\hline & & & $\mathrm{CO}_{2}$ & $\mathrm{H}_{2} \mathrm{CO}$ & $\mathrm{CO}$ & $\mathrm{CO}_{2}$ & $\mathrm{H}_{2} \mathrm{CO}$ & $\mathrm{CO}$ \\
\hline 1 & Ox. $\mathrm{Zr}$ foil $\left(\mathrm{ZrO}_{2}\right)$ & 0 & 0 & 0 & 0 & 0 & 0 & 0 \\
\hline 2 & CVD prep. $\mathrm{ZrO}_{2}$ on $\mathrm{Cu}$ & $5.54 \times 10^{15}$ & 0 & 0 & 0 & 0 & 0 & 0 \\
\hline 3 & CVD prep. $\mathrm{ZrO}_{2}$ on $\mathrm{Cu}$ & $1.02 \times 10^{16}$ & 0.021 & 0.004 & 0.004 & 0.05 & 0.23 & 0.05 \\
\hline 4 & CVD prep. $\mathrm{ZrO}_{2}$ on $\mathrm{Cu}$ & $9.93 \times 10^{15}$ & 0.020 & 0.010 & 0.008 & $\overline{0.16}$ & 0.23 & 0.09 \\
\hline 5 & CVD prep. $\mathrm{ZrO}_{2}$ on $\mathrm{Cu}$ & $8.99 \times 10^{15}$ & 0.014 & 0.009 & 0.007 & 0.12 & 0.18 & 0.09 \\
\hline 6 & CVD prep. $\mathrm{ZrO}_{2}$ on $\mathrm{Cu}$ & $9.03 \times 10^{15}$ & 0.017 & 0.012 & 0.010 & 0.15 & 0.22 & 0.13 \\
\hline 7 & Polycrystalline $\mathrm{Cu}$ foil & $1.16 \times 10^{16}$ & 0 & 0 & 0 & 0 & 0 & 0 \\
\hline
\end{tabular}

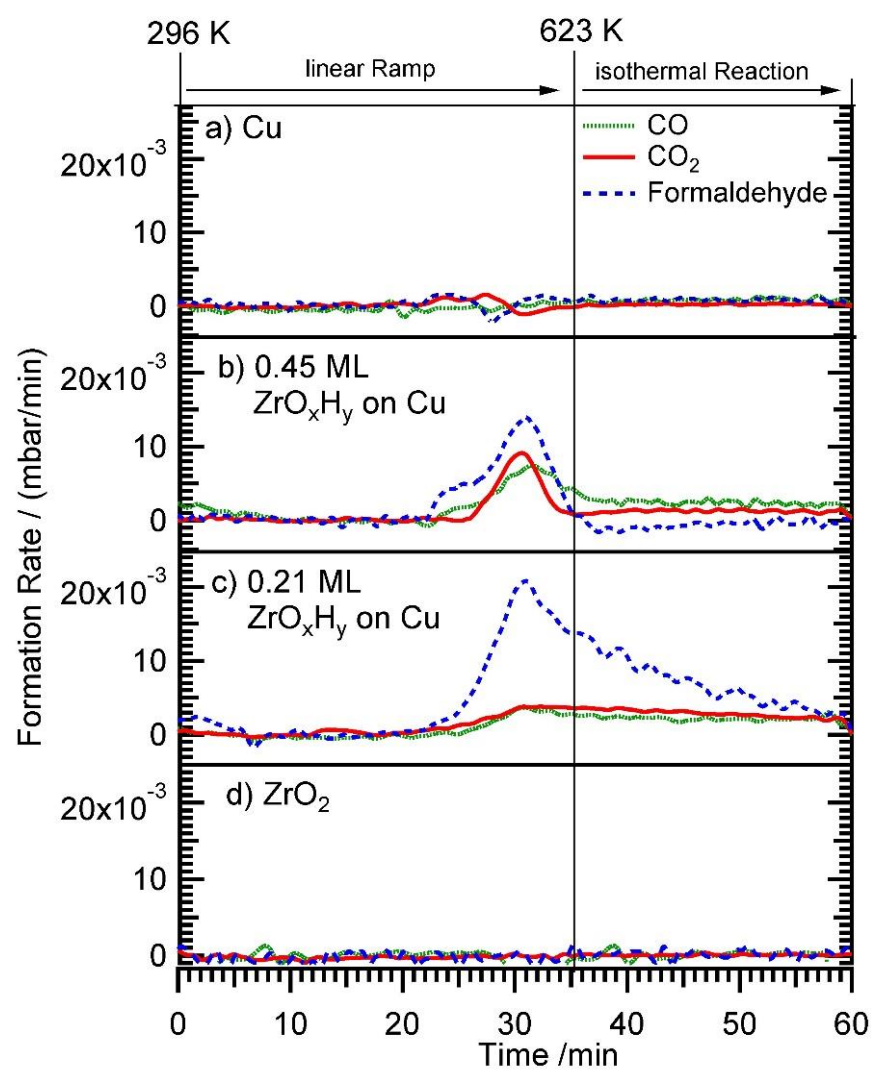

Figure 6: MSR experiments for a) clean $\mathrm{Cu}$, b) Sample 5: $\mathrm{ZrO}_{\mathrm{x}} \mathrm{H}_{\mathrm{y}}(0.45 \mathrm{ML})$ on $\mathrm{Cu}$ foil, c) Sample 3: $\mathrm{ZrO}_{\mathrm{x}} \mathrm{H}_{\mathrm{y}}$ on $\mathrm{Cu}$ foil $(0.21 \mathrm{ML})$ and d) clean $\mathrm{ZrO}_{2}$. Reaction conditions: 12 mbar methanol, 24 mbar water, 8 mbar Argon and He added to 1 bar total pressure. After an 
equilibration time of $10 \mathrm{~min}$, a temperature ramp of $10 \mathrm{~K} \mathrm{~min}^{-1}$ up to $623 \mathrm{~K}$ was set, followed by an isothermal period at $623 \mathrm{~K}$.

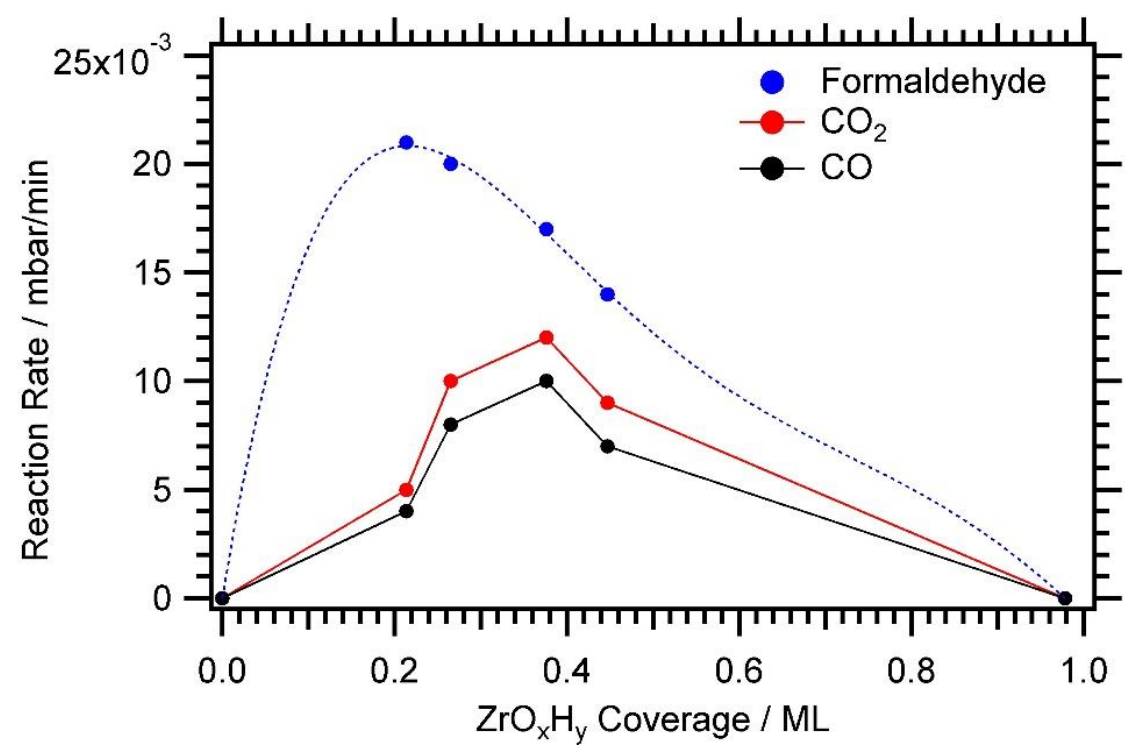

Figure 7: Plot of reaction rate versus $\mathrm{ZrO}_{\mathrm{x}} \mathrm{H}_{\mathrm{y}}$ coverage as estimated from XPS. The $\mathrm{CO} / \mathrm{CO}_{2}$ rate maximum does not coincide with the formaldehyde maximum, as a consequence of different reaction sites for partial dehydrogenation, $\mathrm{H}_{2}$ desorption and total oxidation.

By varying the thickness of the $\mathrm{ZrO}_{x} \mathrm{H}_{y}$ overlayer on the $\mathrm{Cu}$ substrate (i.e. the extent and chemical nature of the $\mathrm{ZrO}_{\mathrm{x}} \mathrm{H}_{\mathrm{y}} / \mathrm{Cu}$ interface) beneficial and disadvantageous selectivity steering bi-functional synergisms can directly be determined and correlated with the spectroscopic and structural results (shown above) to establish direct structure-activity and selectivity relationships. The related spectroscopic data for the 7 samples (six of them shown in Figure 7) can be found in XPS section 3.C.

The reactivity pattern of $\mathrm{CVD}$ prepared $\mathrm{ZrO}_{\mathrm{x}} \mathrm{H}_{\mathrm{y}}$ on $\mathrm{Cu}$ differs from what to expect from the deliberate hydroxylation and the abilities of sputter-deposited $\mathrm{ZrO}_{\mathrm{x}} \mathrm{H}_{\mathrm{y}}$ on $\mathrm{Cu}$ [15]. At first, it appears surprising that no MSR-effective $\mathrm{H}_{2} \mathrm{O}$ activation could be observed, but a selectivity shift towards formaldehyde especially for low $\mathrm{ZrO}_{\mathrm{x}} \mathrm{H}_{\mathrm{y}}$ coverages was confirmed (see Figure 7). This finding is interesting from two points of view: firstly, $\mathrm{Cu}$ is activated by the $\mathrm{ZrO}_{\mathrm{x}} \mathrm{H}_{\mathrm{y}}$ 
CVD preparation similar to the pre-activation with co-fed $\mathrm{O}_{2}$, but more efficiently. The ability of pure $\mathrm{Cu}$ to activate methanol is increased with $\mathrm{O}_{\text {sub }}$ in the $\mathrm{Cu}$ lattice [4]. Alternatively, the oxidized/hydroxylated $\mathrm{Zr}$ species could also take the role of altering the $\mathrm{Cu}$ lattice [36].

The observed activation could in principle also be associated with an effect of electronic modification (and thus, catalytic activation of the thin oxide layer by the $\mathrm{Cu}$ substrate) as the mean overlayer thickness estimated from combined XPS/ISS results and from DFT calculations is preferentially around $2 \mathrm{ML}$ (cf. Figure S3). However, the formaldehyde formation rate decreases with higher $\mathrm{ZrO}_{\mathrm{x}} \mathrm{H}_{\mathrm{y}}$ coverage, despite this constant layer thickness, which contradicts a purely oxide-surface related promotion.

In fact, the formaldehyde rate maximum does not coincide with the rate maxima of $\mathrm{CO}$ and $\mathrm{CO}_{2}$. Expectedly, a reaction mechanism occurring directly at a geometrically optimized number of $\mathrm{Cu} / \mathrm{ZrO}_{\mathrm{x}} \mathrm{H}_{\mathrm{y}}$ interfacial sites should give rise to a rate maximum around coverage of 0.5 (see Figure 7). However, it rather appears that the formaldehyde formation rate is correlated with a relatively large fraction of chemically unaltered and/or free $\mathrm{Cu}$ metal surface sites, as it reaches its maximum at rather low $\mathrm{ZrO}_{\mathrm{x}} \mathrm{H}_{\mathrm{y}}$ coverages around 0.2 ML. We, thus, rather suggest a mechanism involving "structure-insensitive" selective dehydrogenation of methanol to formaldehyde (desorbing directly to the gas phase) on extended clean $\mathrm{Cu}$ surface patches, followed by relatively fast diffusion of the simultaneously formed $\mathrm{H}$ atoms over mesoscopic distances to nearby phase boundary sites, which eventually help to lower the intrinsically high $\mathrm{H}_{2}$ desorption barrier on the clean $\mathrm{Cu}$ surface. In this "H-surface diffusion" scenario, the optimum phase boundary dimensions are most likely below the $0.5 \mathrm{ML}$ "geometric" optimum.

On the CVD-prepared system, up to $623 \mathrm{~K}$ only inefficient onward reaction with activated water takes place, represented by the overall low $\mathrm{CO}_{2}$ formation rate shown in Figures 6 and 7. A relative maximum of $\mathrm{CO}_{2}$ production was observed on the $0.45 \mathrm{ML} \mathrm{ZrO}_{\mathrm{x}} \mathrm{H}_{\mathrm{y}}$ covered 
surface, suggesting a slightly improved total oxidation reaction channel at the "geometric" phase boundary optimum.

\section{B.3. CVD prepared $\mathrm{ZrO}_{x} \mathrm{H}_{y}$ in MSR up to $873 \mathrm{~K}$ and the role of hydroxylation}

In situ XP spectra were recorded under MSR conditions (total pressure 0.3 mbar, methanol:water=1:2) and the respective results are shown in Figure 8. After the CVD growth at $693 \mathrm{~K}$, the sample was cooled to room temperature and exposed to the MSR gas phase (first spectrum). The initial CVD-induced hydroxyl species are largely decomposed around $550 \mathrm{~K}$ and hydroxylation is hardly re-established until $623 \mathrm{~K}$, resulting in a $\mathrm{Zr} 3 \mathrm{~d}$ peak shift down to a BE of $182.4 \mathrm{eV}$ (literature value for bulk $\mathrm{ZrO}_{2}$ [33]). Relevant temperatures for a good MSR catalyst are rather below $623 \mathrm{~K}$. Thus, this maximum temperature was chosen for the previous catalytic experiments of Figure 6, which, as a consequence of dehydroxylation, show only little $\mathrm{CO}_{2}$-formation in this temperature range. Moreover, the data of Figure 8 confirm the previously only "ex situ - XPS" observed dehydroxylation of $\mathrm{ZrO}_{\mathrm{x}} \mathrm{H}_{\mathrm{y}}$ after the MSR experiments at $623 \mathrm{~K}$ (cf. Figure 6). With further increasing temperature, again an increasing degree of hydroxylation is observed, as indicated by the $\mathrm{Zr} 3 \mathrm{~d}$ peak shift to higher binding energies. This "high-temperature" hydroxylation most likely arises from now kinetically accessible water activation pathways. In order to understand the catalytic consequences of this effect, a corresponding temperature-programmed MSR experiment was performed up to a maximum temperature of $873 \mathrm{~K}$ (Figure 9). 


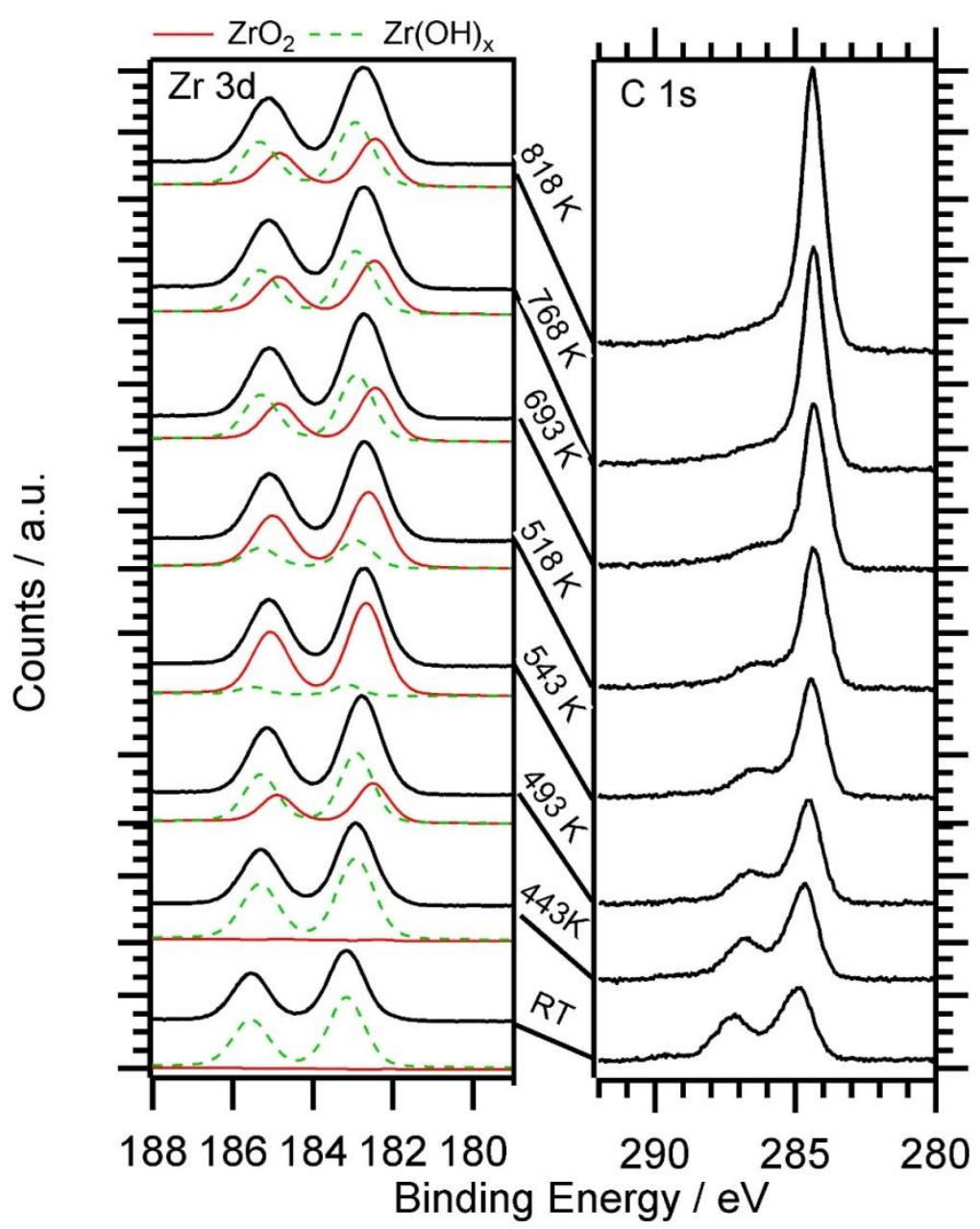

Figure 8: In situ XP spectra of a $\mathrm{ZrO}_{\mathrm{x}} \mathrm{H}_{\mathrm{y}}$ overlayer ( 0.5 ML) on the polycrystalline $\mathrm{Cu}$ foil. Initial hydroxylation after the CVD process is depleted until $\sim 550 \mathrm{~K}$, but hydroxyl groups are then re-established at higher temperatures. This "high-temperature" water activation opens the total oxidation pathway as shown in Figure 9. MSR conditions: 0.1 mbar methanol, 0.2 mbar $\mathrm{H}_{2} \mathrm{O}$.

A significantly higher $\mathrm{CO}_{2}$ formation rate than on clean $\mathrm{Cu}$ could be detected in the

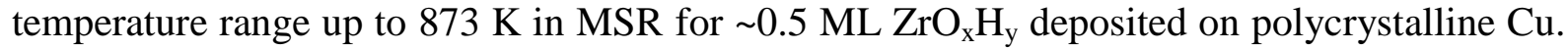
$\mathrm{CO}_{2}$ can now be formed via the reaction of activated methanol and activated water above $\sim 700 \mathrm{~K}$, in agreement with the re-hydroxylation beyond $\sim 623 \mathrm{~K}$ shown in Figure $8 . \mathrm{CO}$ formed above $\sim 700 \mathrm{~K}$ via the inverse water gas shift reaction decreases the $\mathrm{CO}_{2}$-selectivity of the catalyst at higher reaction temperatures. 


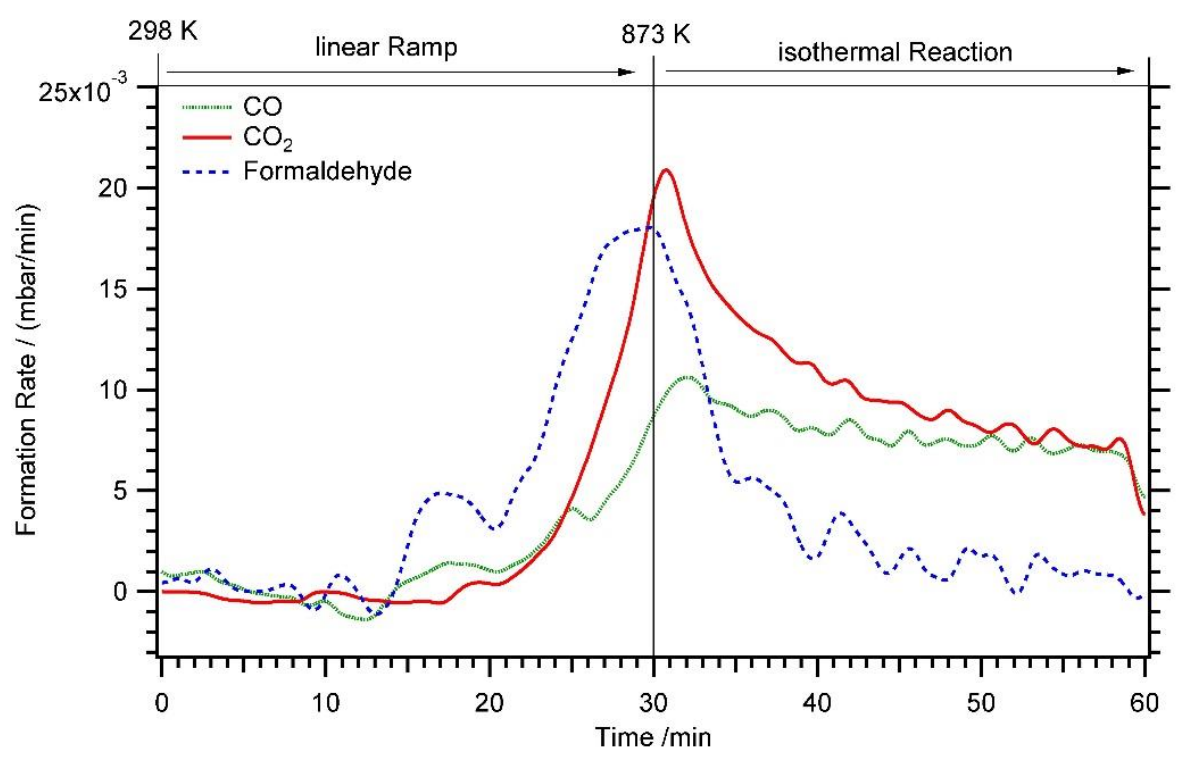

Figure 9: MSR experiment up to $873 \mathrm{~K}$ on polycrystalline $\mathrm{Cu}$ modified by $\sim 0.5 \mathrm{ML} \mathrm{ZrO}_{\mathrm{x}} \mathrm{H}_{\mathrm{y}}$. $\mathrm{CO}_{2}$ is formed above $\sim 623 \mathrm{~K}$, as water activation-dependent reaction pathways become accessible (cf. XPS data in Figure 8).

Phenomenologically, the loss of $-\mathrm{OH}$ groups while heating up to $623 \mathrm{~K}$ (in situ data of Figure 8) and, as a lookahead, the (ex situ verified) absence of the latter after MSR at $623 \mathrm{~K}$ (cf. Figure 11 and Table 5 in section 3.C.), suggest a too weak bonding of at least the originally present CVD-preparation-induced $-\mathrm{OH}$ groups under stationary reaction conditions. This is clear especially in comparison to the sputter-prepared "intermetallic pre-catalyst" state. The latter shows a considerably higher $\mathrm{CO}_{2}$ selectivity in combination with "active" hydroxylation at $623 \mathrm{~K}$ under otherwise identical conditions [14].

From a very general viewpoint, for MSR the reaction of intermediate formaldehyde with sufficiently stable (but not too stable) - $\mathrm{OH}$ groups to $\mathrm{CO}_{2}$ represents the most crucial reaction step, being intimately linked to efficient and reversible water activation [37]. In analogy to the "bifunctional" mechanism postulated for the $\mathrm{Cu} / \mathrm{ZnO}_{\mathrm{x}}$ system [13], we suggest that methanol is activated and formaldehyde formed on $\mathrm{Cu}$ sites and the reactive $-\mathrm{OH}$ species need to be formed continuously at the $\mathrm{Cu} / \mathrm{ZrO}_{\mathrm{x}} \mathrm{H}_{\mathrm{y}}$ interface. 
In case of the initially intermetallic $\mathrm{Cu} / \mathrm{Zr}^{0}$ pre-catalyst, metallic $\mathrm{Zr}^{0}$ is (as a consequence of the sputter process) rather statistically distributed in/on $\mathrm{Cu}$, likely leading to highly dispersed and hydroxylated $\mathrm{ZrO}_{\mathrm{x}} \mathrm{H}_{\mathrm{y}}$ species upon reaction with water at $623 \mathrm{~K}$ under MSR conditions [15]. Obviously, the highly specific intermetallic precursor state somehow allows reversible water splitting/ Zr hydroxylation already at temperatures around $600 \mathrm{~K}$. In contrast, on the CVD-prepared phase boundary the analogous bifunctional situation is only established at much higher temperatures around $700 \mathrm{~K}$, as will be demonstrated in the following chapter

\section{B.3.}

At present it would remain pure speculation why the barriers for heterolytic water splitting and the stabilities of the resulting - $\mathrm{OH}$ groups are considerably different for the CVD- and sputter-prepared model catalysts. In the absence of detailed structural information regarding the dimensions, the chemical and the structural (polymorphic) nature of the two phase boundary models, we limit ourselves to the presentation of the phenomenological results.

\section{B.4. Methanol steam reforming after oxidative treatments}

If the CVD-prepared films are exposed to $\mathrm{O}_{2}$ at $673 \mathrm{~K}$ prior to MSR (with $623 \mathrm{~K}$ maximum temperature), all formation rates are without exception lowered. The MSR selectivity pattern and activity shown in panel b) in Figure 10 was obtained after heating for 5 min at $673 \mathrm{~K}$ in $5 \times 10^{-7}$ mbar $\mathrm{O}_{2}$. The reaction rates are significantly reduced, as compared to the "as-grown" sample in panel a). Further heating for $10 \mathrm{~min}$ under the same oxidative conditions at the same temperature leads to an almost complete loss of activity, as shown in panel c).

As revealed in the post-treatment study (section 3.A.4), initially present $\mathrm{Zr}-\mathrm{OH}$ species are depleted by the oxygen treatments, although, as shown by HREELS, not instantly and completely. The general loss of activity can therefore be correlated with the loss of $\mathrm{Zr}-\mathrm{OH}$ groups. This implies that a certain degree of hydroxylation is also important for partial 
oxidation of methanol to formaldehyde and that the promotion of $\mathrm{H}_{2}$ desorption by the $\mathrm{ZrO}_{\mathrm{x}} \mathrm{H}_{\mathrm{y}}$ islands (as suggested in section 3.B.2) is somehow also linked to the presence of $-\mathrm{OH}$ species.

This result allows to speculate about the role of $\mathrm{Zr}-\mathrm{OH}$ groups in the MSR mechanism. It is plausible that there are two different kinds of $\mathrm{Zr}-\mathrm{OH}$ groups, those at the interface with $\mathrm{Cu}$ and those on $\mathrm{ZrO}_{\mathrm{x}} \mathrm{H}_{\mathrm{y}}$ islands, not being accessible from interfacial sites. These non-interfacial $\mathrm{Zr}-\mathrm{OH}$ species can be reached by $-\mathrm{H}$ atoms via hydrogen spillover on the oxide resulting in $\mathrm{H}_{2}$ clean-off and consequently, partial oxidation activity. Interfacial $\mathrm{Zr}-\mathrm{OH}$ groups, however, might not only catalyze $\mathrm{H}_{2}$ formation, but also trigger full oxidation either by reaction with $\mathrm{Cu}$-activated methanol itself or, probably more likely, by providing $-\mathrm{OH}$ groups by water activation at the surface that can then react with activated methanol species.

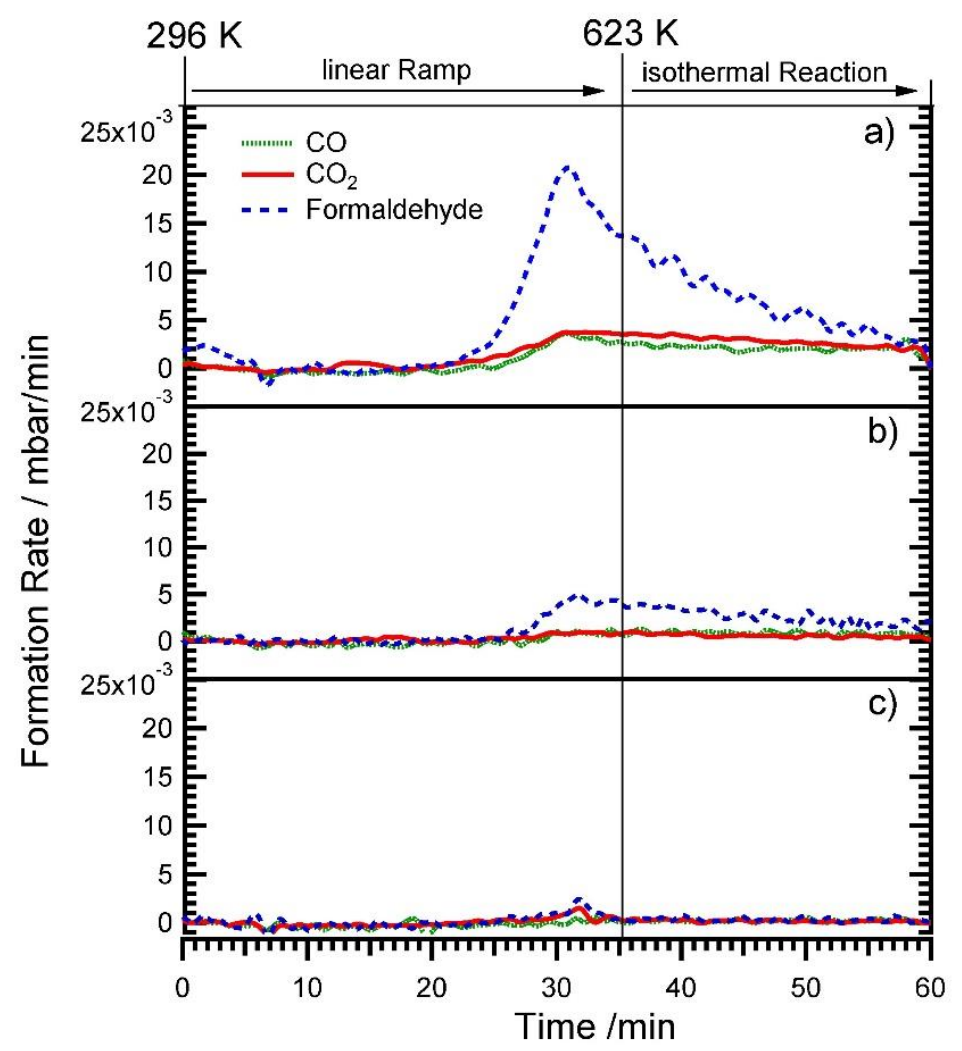

Figure 10: Methanol steam reforming reaction on a $\mathrm{ZrO}_{\mathrm{x}} \mathrm{H}_{\mathrm{y}} / \mathrm{Cu}$ sample, prepared using 2000 L ZTB at $693 \mathrm{~K}$, panel a) (corresponding to a coverage $0.21 \mathrm{ML}$ ). The sample was 
subsequently treated in $\mathrm{O}_{2}$ for $5 \mathrm{~min}$ at $5 \times 10^{-7} \mathrm{mbar}_{2}$ (b) and for $10 \mathrm{~min}$ at $5 \times 10^{-7} \mathrm{mbar} \mathrm{O}_{2}$ (c), both at $673 \mathrm{~K}$. Reaction conditions: 12 mbar Methanol, 24 mbar water, 8 mbar Argon and He added to 1 bar total pressure. After an equilibration period of $10 \mathrm{~min}$, a temperature ramp of $10 \mathrm{~K} \mathrm{~min}^{-1}$ up to $623 \mathrm{~K}$ was set, followed by an isothermal period at $623 \mathrm{~K}$.

\section{C. XP spectroscopy before and after methanol steam reforming}

With the discussed (de)hydroxylation behavior of the films obtained by several treatments in mind, the state of the film after a catalytic MSR reaction is particularly worthwhile to discuss. For the most direct comparison to the catalytic experiments, characterization was carried out on the polycrystalline $\mathrm{Cu}$ foil instead of on a $\mathrm{Cu}(111)$ single crystal. The obtained film after CVD (2000 L at $693 \mathrm{~K})$ in the as-prepared state is very similar to that of the single crystal: A

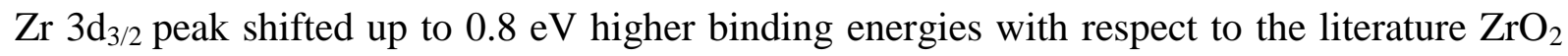
position and $\mathrm{O} 1 \mathrm{~s}$ binding energy that is significantly higher than for oxygen in $\mathrm{ZrO}_{2}$ results. A shoulder towards lower binding energy is noticeable for the $\mathrm{Zr} 3 \mathrm{~d}$ as well as for the $\mathrm{O} 1 \mathrm{~s}$ peak, indicating the presence of a rather small fraction of $\mathrm{ZrO}_{2}$ already in the "as-grown" state (Figure 11).

It is worth noting that a metallic $\mathrm{Cu}$ peak at a highly constant $\mathrm{BE}$ of $932.9 \mathrm{eV}$ is always found in any experiment. However, $\mathrm{Cu}$ in neither of the above-discussed treatments (nor after the catalytic reaction) shows a trend to form oxides, being clearly indicated by the strict absence of a satellite peak around $944.0 \mathrm{eV}$.

After catalysis, all peaks except $\mathrm{Cu} 2 \mathrm{p}$ shift. For the $\mathrm{Zr} 3 \mathrm{~d}_{3 / 2}$ it is safe to state that a loss of hydroxyl groups takes place. This is determined from the $\mathrm{Zr} 3 \mathrm{~d}$ peak position that approaches the literature position for $\mathrm{ZrO}_{2}$ [33] and the comparison with the data on the single crystal and correlating HREEL spectra (section 3.A.). A minor distribution of an even further down shifted state even slightly below ( $\mathrm{Zr} 3 \mathrm{~d}$ peak after reaction $182.3-182.0 \mathrm{eV}$ ) the $\mathrm{ZrO}_{2}$ bulk position is found. This shift is very similar to what was found (in a more pronounced way) 
after oxygen treatment of a $\mathrm{ZrO}_{\mathrm{x}} \mathrm{H}_{\mathrm{y}}$ overlayer, causing the above-described deactivation. Obviously, an oxidative deactivation also during MSR takes place. The $\mathrm{O}$ 1s binding energy approaches $530.4 \mathrm{eV}$, the literature $\mathrm{BE}$ for $\mathrm{ZrO}_{2}$, with a slight shoulder towards lower $\mathrm{BE}$.

Note that neither under reductive conditions nor under $\mathrm{H}_{2} \mathrm{O}$ treatments such a $\mathrm{Zr} 3 \mathrm{~d}_{3 / 2}$ binding energy shift was found. Obviously, the specific MSR mechanism destabilizes the OH groups, (e.g. via reactive consumption toward the hydroxymethoxy intermediate [37]), but they can be preserved under $\mathrm{H}_{2} \mathrm{O}$ or $\mathrm{H}_{2}$ treatments (and under any other reductive conditions). A new component in the $\mathrm{C} 1 \mathrm{~s}$ spectra with a $\mathrm{BE}$ of around $284.3 \mathrm{eV}$ appears after the MSR experiment and is interpreted as near-surface $\mathrm{sp}^{3}$ carbon.

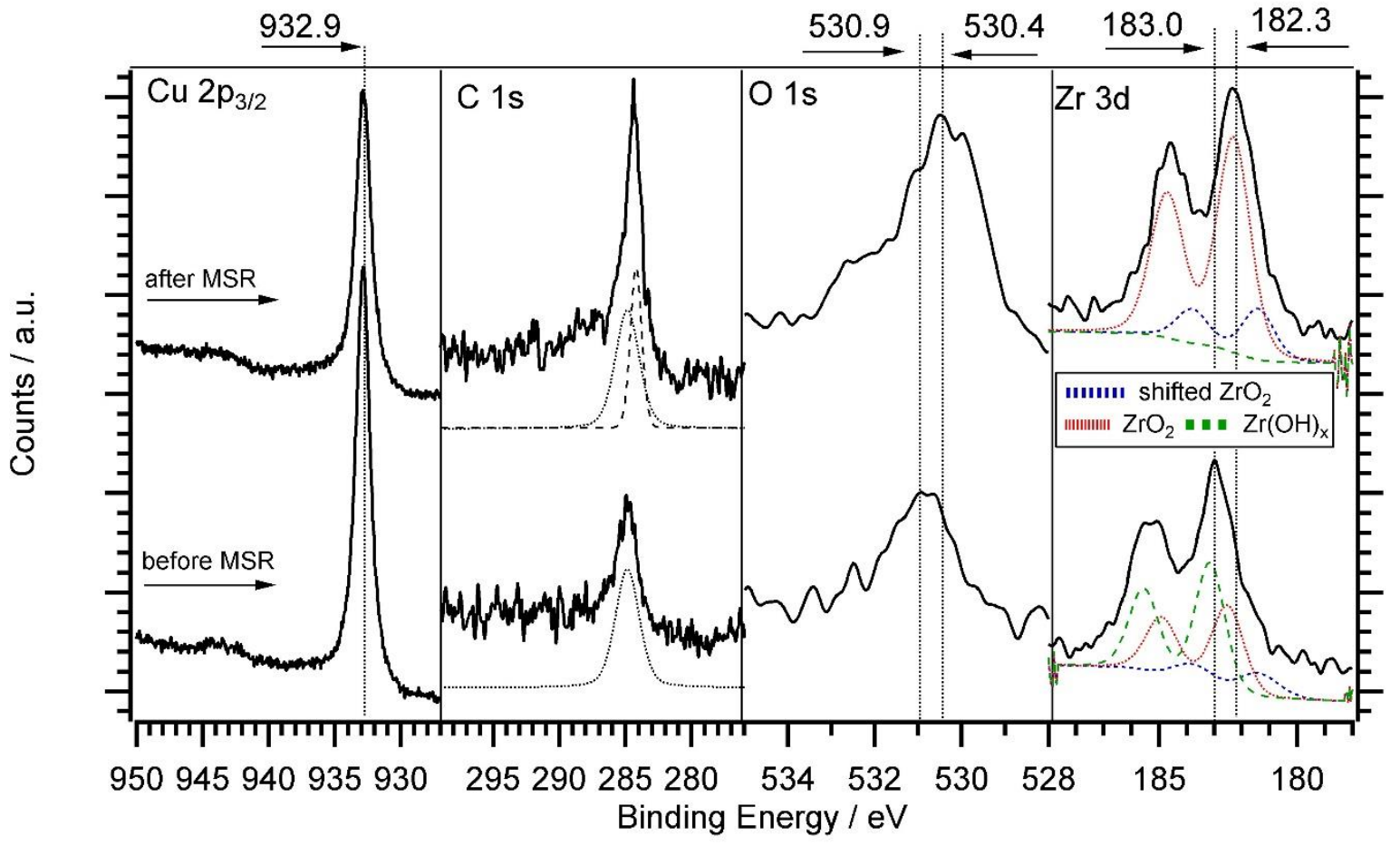

Figure 11: Representative XP spectra collected on the CVD-prepared $\mathrm{ZrO}_{\mathrm{x}} \mathrm{H}_{\mathrm{y}} / \mathrm{Cu}$ foil before and after the MSR experiment. The peak shifts indicate dehydroxylation of the overlayer being comparable to the post-oxidative treatments described above.

As outlined earlier, for the catalytic experiments, seven samples with varying ZTB dosing (in Langmuir), resulting in various $\mathrm{ZrO}_{\mathrm{x}} \mathrm{H}_{\mathrm{y}}$ coverages, have been prepared. Sample 1 is an 
overlayer that was so thick, that no $\mathrm{Cu}$ could be seen either with XPS or ISS (>5000 L), whereas Sample 7 represents clean $\mathrm{Cu}$. For sample 2-6, the exposure was varied between 50 and 5000 L. As described in the experimental section (2.4.), two different XPS overlayer models were applied to all films to estimate the substrate coverage/overlayer thickness. The results are listed in Tables 4 and 5.

The $\mathrm{C} 1 \mathrm{~s}$ binding energy in Table 4 shows a tendency towards lower binding energy after MSR. This is due to the different chemical nature of carbon stemming from the ZTB precursor and the C 1s species arising from the decomposition of methanol. However, all carbon found is $\mathrm{sp}^{3}$-type. The $\mathrm{O} 1 \mathrm{~s}$ region shows a superposition of many states (also including carbon oxygenates), a peak deconvolution therefore was not performed. For the $\mathrm{Zr}$ coverage estimation, it is necessary to state the limitation of the coverage calculation caused by the neglect of the electron attenuation. Especially when a high carbon coverage after MSR appears, the model pretends an increasing Zr coverage with MSR. However, this is an artefact due the shielding of the $\mathrm{Cu} 2 \mathrm{p}_{3 / 2}$ signal and a consequently higher $\mathrm{Zr} / \mathrm{Cu}$ ratio obtained by the calculations. With this limitation in mind, the coverage model nevertheless gives a quantitative insight and can be furthermore correlated with catalytic results. For the $\mathrm{Zr} 3 \mathrm{~d}_{3 / 2}$ peak position a similar shift as discussed above was observed for all samples, with the measured binding energies also listed in Table 4.

Further, in Table 5 the XPS results are combined with ion scattering quantification (selected data in Figure S4). Note that the XPS atomic percent data are only listed for informative reasons but do not represent a reliable basis for interpretation due to the approximation of a homogeneous sample. This is clearly not the case in our substrate-overlayer model. The XPS thickness calculation (considering electron attenuation through the overlayer) with a film thickness (in $\mathrm{nm}$ ) as result are very close to the coverage estimation (no electron attenuation considered) because of the low coverage and the consequently low impact of photoelectron shielding by the overlayer. A mean particle height was estimated from XPS coverage and ISS 
and is close to $2 \mathrm{ML}$ on average for all samples. The propensity to form 1-2 ML ultrathin layers was also highlighted in the DFT calculations (Figure S3).

Table 4: XPS analysis of the $\mathrm{Cu}$ foil covered with different amounts of $\mathrm{ZrO}_{\mathrm{x}} \mathrm{H}_{\mathrm{y}}$ (as outlined in Table 5) before and after the catalytic methanol steam reforming reaction.

\begin{tabular}{|l|c|c|c|c|c|}
\hline \multirow{2}{*}{ Sample } & \multicolumn{2}{|c|}{ C 1s } & O 1s & \multicolumn{2}{c|}{ Zr 3d } \\
\cline { 2 - 5 } & $\begin{array}{c}\text { Coverage / } \\
\text { ML }\end{array}$ & $\begin{array}{c}\text { Peak Position / } \\
\mathrm{eV}\end{array}$ & Peak Position / eV & Coverage /ML & $\begin{array}{c}\text { Zr 3d } \mathrm{d}_{5 / 2} \text { Peak } \\
\text { Position /eV }\end{array}$ \\
\hline 2, before MSR & 0.79 & 284.6 & 531.0 & 1.00 & 182.8 \\
\hline 2, after MSR & 3.10 & 284.5 & 531.7 & $(1.60)$ & 182.3 \\
\hline 3, before MSR & 0.14 & 284.8 & 531.4 & 0.21 & 182.6 \\
\hline 3, after MSR & 0.91 & 284.7 & 531.2 & 0.27 & 182.0 \\
\hline 4, before MSR & 0.60 & 284.6 & 531.8 & 0.27 & 182.6 \\
\hline 4, after MSR & 1.80 & 284.6 & 531.9 & 0.21 & 182.0 \\
\hline 5, before MSR & 0.43 & 284.9 & 531.1 & 0.45 & 183.0 \\
\hline 5, after MSR & 1.71 & 284.4 & 532.0 & 0.52 & 182.3 \\
\hline 6, before MSR & 1.53 & 284.8 & 531.2 & 0.38 & 182.7 \\
\hline 6, after MSR & 3.50 & 284.6 & 531.6 & $0.83)$ & 182.1 \\
\hline
\end{tabular}

Table 5: XPS and ISS data and interpretation of the seven catalytic samples, i.e. of the Cu foil covered with different amounts of $\mathrm{ZrO}_{x} \mathrm{H}_{y}$.

\begin{tabular}{|c|c|c|c|c|c|}
\hline $\begin{array}{c}\text { Sample } \\
\text { No. }\end{array}$ & XPS / atomic\% Zr & ISS / \% Zr & $\begin{array}{c}\text { XPS coverage } \\
\text { / ML }\end{array}$ & $\begin{array}{c}\text { XPS thickness / } \\
\text { nm }\end{array}$ & $\begin{array}{c}\text { mean particle } \\
\text { height / ML }\end{array}$ \\
\hline 1 & 100 & 100 & inf. & inf. & n.a. \\
\hline 2 & 10.1 & 52.00 & 1.00 & 0.51 & 2.00 \\
\hline 3 & 3.00 & 11.49 & 0.21 & 0.11 & 1.90 \\
\hline 4 & 3.10 & 14.10 & 0.27 & 0.14 & 1.90 \\
\hline 5 & 5.50 & 22.20 & 0.45 & 0.24 & 2.00 \\
\hline 6 & 3.30 & 21.80 & 0.38 & 0.20 & 1.70 \\
\hline 7 & 0.00 & 0.00 & 0.00 & 0.00 & 0.00 \\
\hline
\end{tabular}

\section{Conclusions}

In conclusion, chemical vapor deposition of $\mathrm{ZTB}$ on $\mathrm{Cu}$ samples leads to a partially hydroxylated and fully oxidized $\mathrm{Zr}^{+4} \mathrm{O}_{x} \mathrm{H}_{y}$ species, which exhibits a pronounced catalytic synergism between the $\mathrm{ZrO}_{\mathrm{x}} \mathrm{H}_{\mathrm{y}}$ overlayer in the sub-monolayer regime and $\mathrm{Cu}$. The catalytic 
performance differs from that of sputter-grown $\mathrm{ZrO}_{\mathrm{x}} \mathrm{H}_{\mathrm{y}}$ layers on $\mathrm{Cu}$, which exhibit a partially oxidized $\mathrm{Zr}^{0}$ metal precursor state. In due course, these CVD-grown $\mathrm{Zr}-\mathrm{OH}$ groups are much less active for water redox chemistry in MSR because reversible hydroxylation under reaction conditions does not take place. Therefore, water activation-dependent pathways are not accessible. However, $\mathrm{Cu}$ indeed gets activated and this in turn causes increased formaldehyde formation rates, as it is needed for the industrially highly relevant partial oxidation of methanol to formaldehyde. As the most crucial outcome, and further strengthening the assumption that only a dedicated $\mathrm{Cu}-\mathrm{ZrO}_{\mathrm{x}} \mathrm{H}_{\mathrm{y}}$ interface with in situ formed hydroxylated sites in combination with oxygen-poor metallic $\mathrm{Cu} / \mathrm{Zr}$ starting compounds leads to enhanced $\mathrm{CO}_{2}$ selectivity, this appears to be the only way to form the $\mathrm{ZrO}_{x} \mathrm{H}_{y}$ surface structure that is responsible for the necessary $\mathrm{H}_{2} \mathrm{O}$ activation. Although the presented results do obviously not offer a direct pathway to a $\mathrm{Cu} / \mathrm{ZrO}_{\mathrm{x}}$ catalyst with enhanced $\mathrm{CO}_{2}$ selectivity, they clearly lay out the basis for a knowledge-based pathway of catalyst design with enhanced $\mathrm{CO}_{2}$ selectivity, which needs to meet the following criteria: a $\mathrm{Cu} / \mathrm{Zr}$ metallic precursor with $\mathrm{Cu}$ in excess $(\sim 50-70$ at\% $\mathrm{Cu})$ to avoid $\mathrm{ZrO}_{2}$ clustering, oxygen-free preparation to avoid large amounts of oxygen in $\mathrm{Cu}$ and a corresponding post-treatment under MSR conditions for reversible in situ hydroxylation and formation of the $\mathrm{ZrO}_{\mathrm{x}} \mathrm{H}_{\mathrm{y}}-\mathrm{Cu}$ interface.

\section{Acknowledgements}

We thank the FWF (Austrian Science Foundation) for financial support under the SFB F45 project part F4503-N16. The work was performed in the framework of the Forschungsplattform "Advanced Materials" at the University of Innsbruck. The authors thank the HZB/BESSY II staff members Michael Hävecker, Axel Knop-Gericke, and Mark Greiner for their support of the in situ XPS measurements at beamline ISISS-PGM. The authors acknowledge the Purdue Catalysis Center, Michael Detwiler and Amir Gharachorlou for their support of the measurements at the Birck Nanotechnology Center, Purdue University. L.Mayr 
acknowledges financial support via a scholarship of the Carinthian Confederation of Industry (Industriellenvereinigung Kärnten).

\section{References}

[1] K.A. Ali, A.Z. Abdullah, A.R. Mohamed, Recent development in catalytic technologies for methanol synthesis from renewable sources: A critical review, Renewable Sustainable Energy Rev., 44 (2015) 508-518.

[2] M. Behrens, M. Armbrüster, Methanol Steam Reforming, in: L. Guczi, A. Erdôhelyi (Eds.) Catalysis for Alternative Energy Generation, Springer New York, 2012, pp. 175-235.

[3] M. Tada, R. Bal, S. Namba, Y. Iwasawa, Surfactant-promoted novel synthesis of supported metallic $\mathrm{Cu}$ nanoparticles active for selective dehydrogenation of methanol, Appl. Catal. A, 307 (2006) 78-84.

[4] H. Bluhm, M. Haevecker, A. Knop-Gericke, E. Kleimenov, R. Schloegl, D. Teschner, V.I. Bukhtiyarov, D.F. Ogletree, M. Salmeron, Methanol Oxidation on a Copper Catalyst Investigated Using in Situ X-ray Photoelectron Spectroscopy, J. Phys. Chem. B 108 (2004) $14340-14347$.

[5] T. Schedel-Niedrig, M. Havecker, A. Knop-Gericke, R. Schlogl, Partial methanol oxidation over copper: Active sites observed by means of in situ X-ray absorption spectroscopy, Phys. Chem. Chem. Phys. 2 (2000) 3473-3481.

[6] H. Purnama, F. Girgsdies, T. Ressler, J.H. Schattka, R.A. Caruso, R. Schomacker, R. Schlogl, Activity and selectivity of a nanostructured $\mathrm{CuO} / \mathrm{ZrO}_{2}$ catalyst in the steam reforming of methanol, Catal. Lett. 94 (2004) 61-68.

[7] S. Velu, K. Suzuki, C.S. Gopinath, H. Yoshida, T. Hattori, XPS, XANES and EXAFS investigations of $\mathrm{CuO} / \mathrm{ZnO} / \mathrm{Al}_{2} \mathrm{O}_{3} / \mathrm{ZrO}_{2}$ mixed oxide catalysts, Phys. Chem. Chem. Phys., 4 (2002) 1990-1999. 
[8] S. Velu, K. Suzuki, M.P. Kapoor, F. Ohashi, T. Osaki, Selective production of hydrogen for fuel cells via oxidative steam reforming of methanol over $\mathrm{CuZnAl}(\mathrm{Zr})$-oxide catalysts, Appl. Catal. A, 213 (2001) 47-63.

[9] G.-S. Wu, D.-S. Mao, G.-Z. Lu, Y. Cao, K.-N. Fan, The Role of the Promoters in Cu Based Catalysts for Methanol Steam Reforming, Catal. Lett. 130 (2009) 177-184.

[10] J.P. Breen, J.R. Ross, Methanol reforming for fuel-cell applications: development of zirconia-containing $\mathrm{Cu}-\mathrm{Zn}-\mathrm{Al}$ catalysts, Catal. Today 51 (1999) 521-533.

[11] H. Purnama, T. Ressler, R.E. Jentoft, H. Soerijanto, R. Schlögl, R. Schomäcker, CO formation/selectivity for steam reforming of methanol with a commercial $\mathrm{CuO} / \mathrm{ZnO} / \mathrm{Al}_{2} \mathrm{O}_{3}$ catalyst, Appl. Catal. A 259 (2004) 83-94.

[12] C. Rameshan, W. Stadlmayr, C. Weilach, S. Penner, H. Lorenz, M. Hävecker, R. Blume, T. Rocha, D. Teschner, A. Knop-Gericke, R. Schlögl, N. Memmel, D. Zemlyanov, G. Rupprechter, B. Klötzer, Subsurface-Controlled CO2 Selectivity of PdZn Near-Surface Alloys in $\mathrm{H}_{2}$ Generation by Methanol Steam Reforming, Angew. Chem. Int. Ed. 49 (2010) 3224-3227.

[13] C. Rameshan, W. Stadlmayr, S. Penner, H. Lorenz, N. Memmel, M. Hävecker, R. Blume, D. Teschner, T. Rocha, D. Zemlyanov, A. Knop-Gericke, R. Schlögl, B. Klötzer, Hydrogen Production by Methanol Steam Reforming on Copper Boosted by Zinc-Assisted Water Activation, Angew. Chem. 124 (2012) 3057-3061.

[14] L. Mayr, B. Klötzer, D. Zemlyanov, S. Penner, Steering of methanol reforming selectivity by zirconia-copper interaction, J. Catal. 321 (2015) 123-132.

[15] A. Knop-Gericke, M. Hävecker, T. Schedel-Niedrig, R. Schlögl, Probing the electronic structure of an active catalyst surface under high-pressure reaction conditions: the oxidation of methanol over copper, Catal. Lett. 66 (2000) 215-220. 
[16] T. Takahashi, M. Inoue, T. Kai, Effect of metal composition on hydrogen selectivity in steam reforming of methanol over catalysts prepared from amorphous alloys, Appl. Catal. A 218 (2001) 189-195.

[17] T. Takahashi, M. Kawabata, T. Kai, H. Kimura, A. Inoue, Preparation of Highly Active Methanol Steam Reforming Catalysts from Glassy Cu-Zr Alloys with Small Amount of Noble Metals, Mater. Trans. 47 (2006) 2081-2085.

[18] N.A. Ray, R.P. Van Duyne, P.C. Stair, Synthesis Strategy for Protected Metal Nanoparticles, J. Phys. Chem. C 116 (2012) 7748-7756.

[19] L. Mayr, R. Rameshan, B. Klötzer, S. Penner, C. Rameshan, Combined UHV/highpressure catalysis setup for depth-resolved near-surface spectroscopic characterization and catalytic testing of model catalysts, Rev. Sci. Instrum. 85 (2014) 055104.

[20] A. Gharachorlou, M.D. Detwiler, X.-K. Gu, L. Mayr, B. Klötzer, J. Greeley, R.G. Reifenberger, W.N. Delgass, F.H. Ribeiro, D.Y. Zemlyanov, Trimethylaluminum and Oxygen Atomic Layer Deposition on Hydroxyl-Free Cu (111), ACS Appl. Mater. Interfaces, 7 (2015) $16428-16439$.

[21] A. Gharachorlou, M.D. Detwiler, L. Mayr, X.-K. Gu, J. Greeley, R.G. Reifenberger, W.N. Delgass, F.H. Ribeiro, D.Y. Zemlyanov, Surface Chemistry of Trimethylaluminum on Pd(111) and Pt(111), J. Phys. Chem. C, 119 (2015) 19059-19072.

[22] D. Starr, Z. Liu, M. Hävecker, A. Knop-Gericke, H. Bluhm, Investigation of solid/vapor interfaces using ambient pressure X-ray photoelectron spectroscopy, Chem. Soc. Rev. 42 (2013) 5833-5857.

[23] C.J. Powell, A. Jablonski, NIST Electron Effective-Attenuation-Length Database SRD 82, National Instititue of Standards and Technology, Gaithersburg, 2011.

[24] J.F.W.a.J. Wolstenholme, An Introduction to Surface Analysis by XPS and AES, WileyVCH Verlag GmbH, Weinheim, 2003. 
[25] C.S. Fadley, Basic concepts of x-ray photoelectron spectroscopy, Electron Spectrosc. Theory, Tech. Appl 2 (1978).

[26] CasaXPS Version 2.3.16 Pre-rel 1.4, in, Casa Software Ltd, 2011.

[27] C.D. Wagner, W.M. Riggs, L.E. Davis, J.F. Moulder, G.E. Muilenberg, Handbook of XRay Photoelectron Spectroscopy, Perkin-Elmer Corporation, Physical Electronics Division, Eden Prairie, Minnesota, 1979.

[28] D. Majumdar, D. Chatterjee, X-ray photoelectron spectroscopic studies on yttria, zirconia, and yttria-stabilized zirconia, J. Appl. Phys. 70 (1991) 988-992.

[29] J.J. Yeh, Atomic Calculation of Photoionization Cross-Sections and Asymmetry Parameters, Gordon and Breach Science Publishers, Langhorne, PE (USA), 1993.

[30] J.P. Chang, Y.-S. Lin, S. Berger, A. Kepten, R. Bloom, S. Levy, Ultrathin zirconium oxide films as alternative gate dielectrics, J. Vac. Sci. Technol. B 19 (2001) 2137-2143.

[31] M.A. Cameron, S.M. George, $\mathrm{ZrO}_{2}$ film growth by chemical vapor deposition using zirconium tetra-tert-butoxide, Thin Solid Films 348 (1999) 90-98.

[32] C. Huang, Z. Tang, Z. Zhang, Differences between Zirconium Hydroxide $\left(\mathrm{Zr}(\mathrm{OH})_{4} \cdot \mathrm{nH}_{2} \mathrm{O}\right)$ and Hydrous Zirconia $\left(\mathrm{ZrO}_{2} \cdot \mathrm{nH}_{2} \mathrm{O}\right)$, J. Am. Ceram. Soc. 84 (2001) 16371638.

[33] C. Sleigh, A.P. Pijpers, A. Jaspers, B. Coussens, R.J. Meier, On the determination of atomic charge via ESCA including application to organometallics, J. Electron Spectrosc. Relat. Phenom. 77 (1996) 41-57.

[34] X.-K. Gu, W.-X. Li, First-Principles Study on the Origin of the Different Selectivities for Methanol Steam Reforming on $\mathrm{Cu}(111)$ and Pd(111), J. Phys. Chem. C 114 (2010) 2153921547.

[35] D.R. Palo, R.A. Dagle, J.D. Holladay, Methanol Steam Reforming for Hydrogen Production, Chem. Rev. 107 (2007) 3992-4021. 
[36] P. Kurr, I. Kasatkin, F. Girgsdies, A. Trunschke, R. Schlögl, T. Ressler, Microstructural characterization of $\mathrm{Cu} / \mathrm{ZnO} / \mathrm{Al}_{2} \mathrm{O}_{3}$ catalysts for methanol steam reforming-A comparative study, Appl. Catal. A 348 (2008) 153-164.

[37] L.C. Grabow, M. Mavrikakis, Mechanism of Methanol Synthesis on $\mathrm{Cu}$ through $\mathrm{CO}_{2}$ and CO Hydrogenation, ACS Catal. 1 (2011) 365-384.

\section{Graphical Abstract}

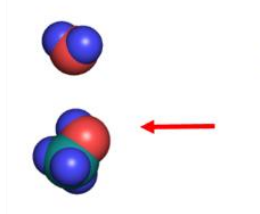

$\mathrm{MeOH}, \mathrm{H}_{2} \mathrm{O}$

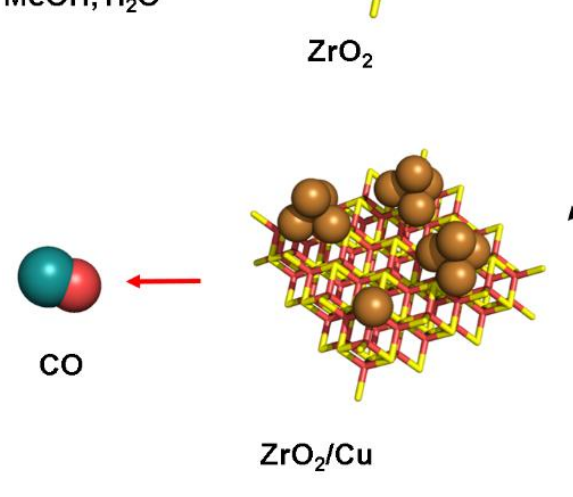

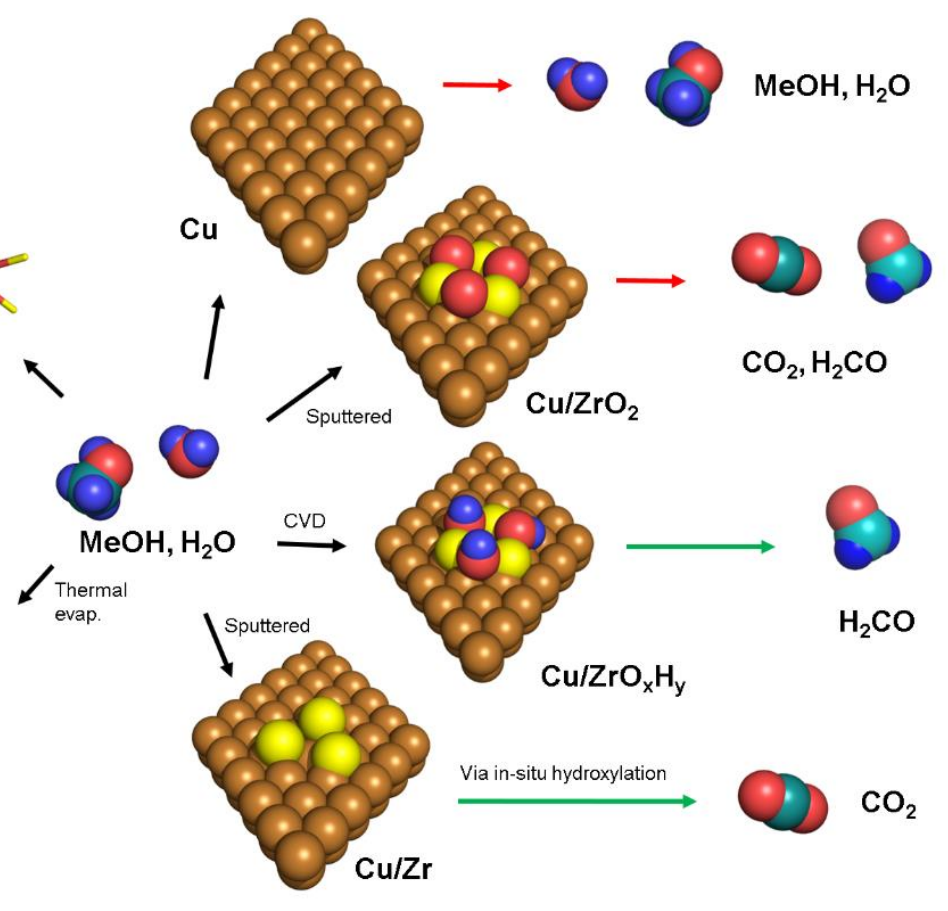

